\title{
The reductive decyanation reaction : chemical methods and synthetic applications
}

\author{
Jean-Marc Mattalia,* Caroline Marchi-Delapierre, Hassan Hazimeh, and Michel Chanon \\ Laboratoire AM3, UMR CNRS 6178, Université Paul Cézanne, Faculté des Sciences \\ de Saint-Jérôme, Case 561, 13397 Marseille Cedex 20, France \\ E-mail: jean-marc.mattalia@univ.u-3mrs.fr
}

\section{Dedicated to Prof. A. Lattes}

\begin{abstract}
Several sequences involving the nitrile group require the removal of this function in a convenient and clean procedure. This transformation, called reductive decyanation, has received much attention over the years. In this review, we describe the chemical methods leading to reductive decyanation as well as the proposed mechanisms. Much of these methodologies proceed with good yields and stereoselectivities allowing their exploitation in organic synthesis.
\end{abstract}

Keywords : Nitrile, reductive decyanation, synthesis, alkali metals, metal hydrides

\section{Table of contents}

Introduction

1. Metal dissolving conditions

2. Alumino- and borohydrides

$2.1 \alpha$-Aminonitriles

2.2 Other cases

3. Acid or base promoted decyanation reactions

4. $\mathrm{Bu}_{3} \mathrm{SnH}$ or $\mathrm{SmI}_{2}$ promoted decyanation reactions

5. Miscellaneous

5.1 Organometallic promoted decyanation reactions

5.2 Sodium dithionite promoted decyanation reactions

5.3 Raney nickel or hydrogenation promoted decyanation reactions

5.4 Hydrolytic decyanation

5.5 Electrochemical cleavage of nitriles

5.6 Transition metals promoted decyanation reactions 


\subsection{Photoinduced decyanations}

Conclusions

References

\section{Introduction}

The use of the nitrile function for $\mathrm{C}-\mathrm{C}$ bond formation reaction occupies an important position in organic chemistry. ${ }^{1-4}$ Especially, deprotonation of the $\alpha$-carbon and alkylation is an important reaction. ${ }^{5}$ The sequences involving the nitrile function usually requires the subsequent removal of the nitrile group in a convenient and clean manner. The reduction of the nitrile group (RCN) is observed with many reducing agents. Depending on the nature of the reducing agent and experimental conditions, the reaction can produce amines, aldehydes, primary alcohol, imines or alkanes $\left(\mathrm{RCH}_{3}\right.$ or $\left.\mathrm{RH}\right){ }^{6}$ The latter transformation, described in Scheme 1, is called reductive decyanation.

\section{Scheme 1}

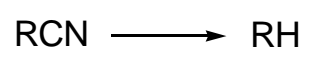

In 1991, we discovered the anomalous reductive decyanation of a $\alpha$-sulfonitrile induced by $\mathrm{LiAlH}_{4}{ }^{7}$ We were then interested in the great variety of procedures allowing this transformation. We realized that, despite a large use of this reduction in organic synthesis these last years, no recent review focused on this topic.

This paper provides an overview of the different routes leading to decyanation. For each of them, experimental conditions and mechanistic aspects will be described. We describe also recent applications in organic synthesis. The purpose of this work is to point out the utility of this reaction through a set of examples. We concentrate on reductive decyanation of nitriles and will not discuss dehydrocyanation, ${ }^{8}$ oxidative decyanation ${ }^{9}$ or reactivity of cyanamides. ${ }^{10}$

\section{Metal dissolving conditions}

Arapakos et al. using sodium biphenyl radical anion, sodium in liquid ammonia or lithiumethylamine solutions found that tertiary nitriles give reductive decyanation products in high yields. ${ }^{11-13}$ The mechanism proposed involves a two electrons transfer with formation of a carbanion via a radical anion. The latter is then protonated by ammonia in situ or by another proton donor depending on the reaction conditions (Scheme 2). ${ }^{11,14-16}$ 


$$
\begin{aligned}
& \mathrm{RCN}+\mathrm{M} \stackrel{\mathrm{e}^{-}}{\longrightarrow} \mathrm{RCN}^{-} \longrightarrow \mathrm{R}^{\bullet}+\mathrm{CN}^{-} \stackrel{\mathrm{e}^{-}}{\longrightarrow} \mathrm{R}^{-} \stackrel{\mathrm{H}^{+}}{\longrightarrow} \mathrm{RH} \\
& \mathrm{M}=\text { metal }
\end{aligned}
$$

\section{Scheme 2}

From the mechanism described above, the stereochemical outcome of these reductions should depend on the behavior of radical and carbanion intermediates as well as on the approach of the proton or, possibly, an hydrogen atom donor. More specific studies show that experimental conditions, additives, nature of the metal play an important role. ${ }^{14,15,17,18}$ Good stereoselectivities are obtained in many cases.

The $\mathrm{Li}$ or $\mathrm{Na} / \mathrm{NH}_{3}$ system has been widely used in organic synthesis. ${ }^{19-27}$ Rychnovsky investigated the alkylation and reductive decyanation of cyanohydrin acetonides such as $\mathbf{1}$ (Scheme 3). ${ }^{28}$ The latter are key intermediates in the synthesis of polyene macrolide antibiotics such as roflamycoin, ${ }^{29} 17$-deoxyroflamycoin ${ }^{30}$ or filipin III. ${ }^{31}$ The observed stereochemistry reflects the configuration preference for an axial anomeric radical. The resulting axial carbanion is then protonated with retention of configuration. ${ }^{32} \mathrm{Ab}$ initio calculations are consistent with this stereochemical outcome. $^{33}$

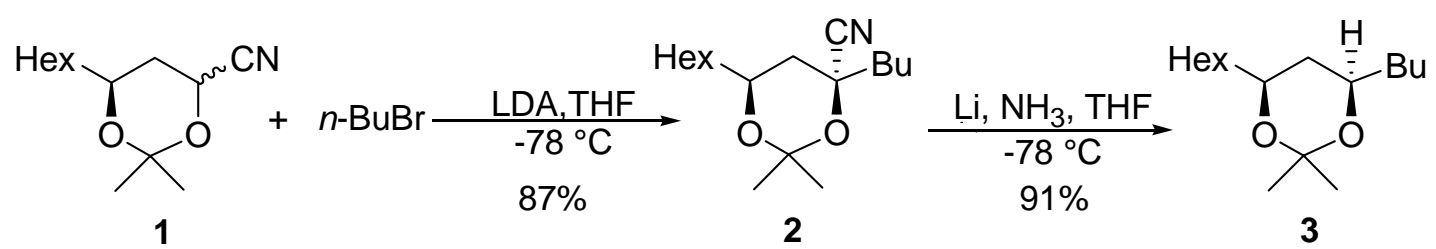

\section{Scheme 3}

During the synthesis of the Galbulimima alkaloid GB 13 , the nitrile group appears as a dienophile activating group in $\mathbf{4}$ and is removed from $\mathbf{5}$ with lithium in $\mathrm{NH}_{3} / \mathrm{THF}$. Addition of ethanol resulted in the Birch reduction of the aromatic ring (Scheme 4). ${ }^{34}$ 

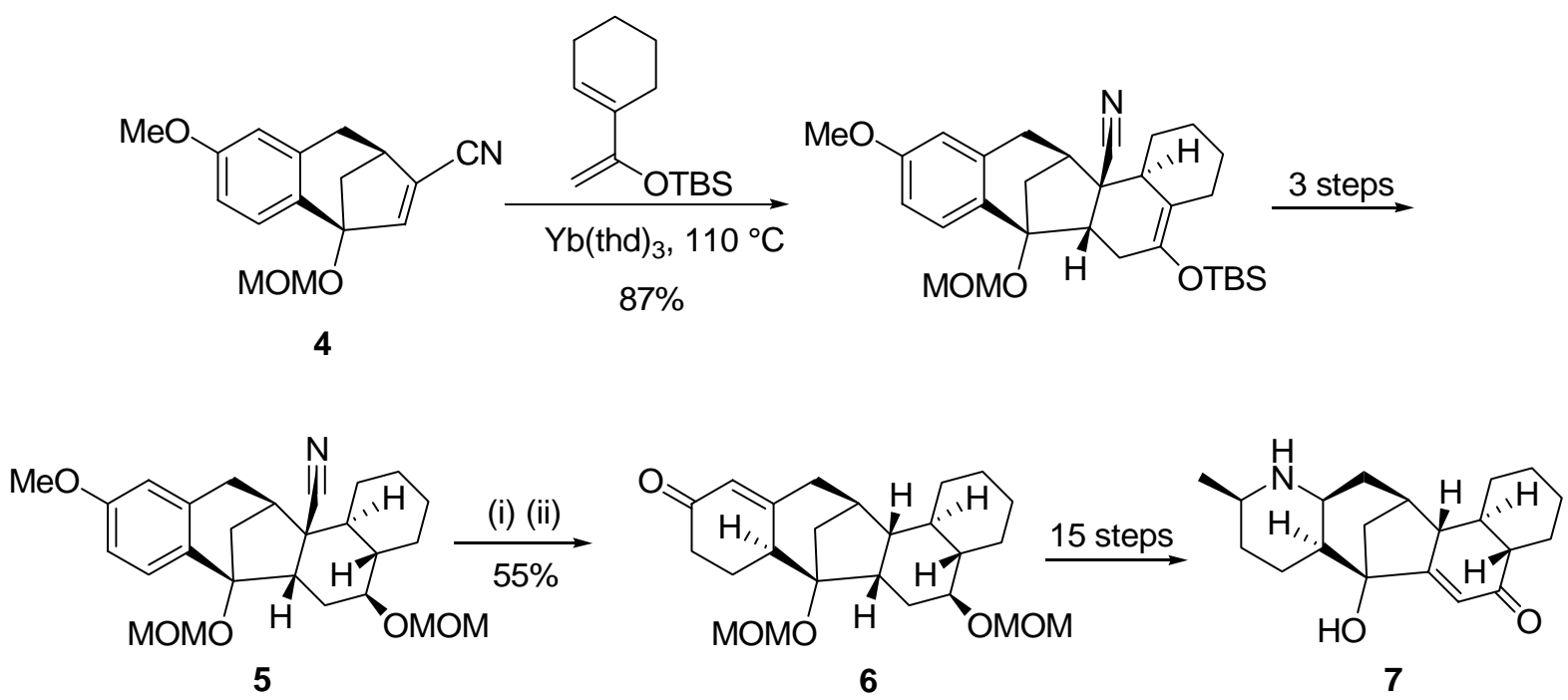

(i) $\mathrm{Li}, \mathrm{NH}_{3}, \mathrm{THF},-78^{\circ} \mathrm{C} \longrightarrow-33^{\circ} \mathrm{C}$ and then $\mathrm{EtOH}$.

(ii) $\mathrm{HCl}, \mathrm{MeOH}, \mathrm{THF}$.

$\mathrm{MOM}=$ methoxymethyl;

$\mathrm{Yb}(\text { thd })_{3}=$ ytterbium tris(2,2,6,6-tetramethyl-3,5-heptane-dionate)

OTBS $=$ tert-butyldimethylsilyloxy

\section{Scheme 4}

The drawback of such reaction conditions is that primary and secondary nitriles give the expected amine as well as decyanation products. ${ }^{11,12,35}$ Several methods were developed to improve the yields. It is possible to break the $\mathrm{C}-\mathrm{CN}$ bond in good yields in HMPA (hexamethylphosphoramide) with $\mathrm{K}$ in the presence of tert-butyl alcohol as protic cosolvent ${ }^{36-38}$ or with high-surface-area potassium on neutral alumina $\left(\mathrm{K} / \mathrm{Al}_{2} \mathrm{O}_{3}\right)$ in hexane. ${ }^{39}$ The radical anion generated from potassium metal/dicyclohexano-18-crown-6/toluene system is also highly effective for the reductive decyanation of primary, secondary and tertiary cyanides. ${ }^{40,41}$ This method was used in the preparation of ent-cholesterol $\mathbf{9}$ after alkylation at the $\alpha$-carbon (Scheme $5) .^{42}$ 


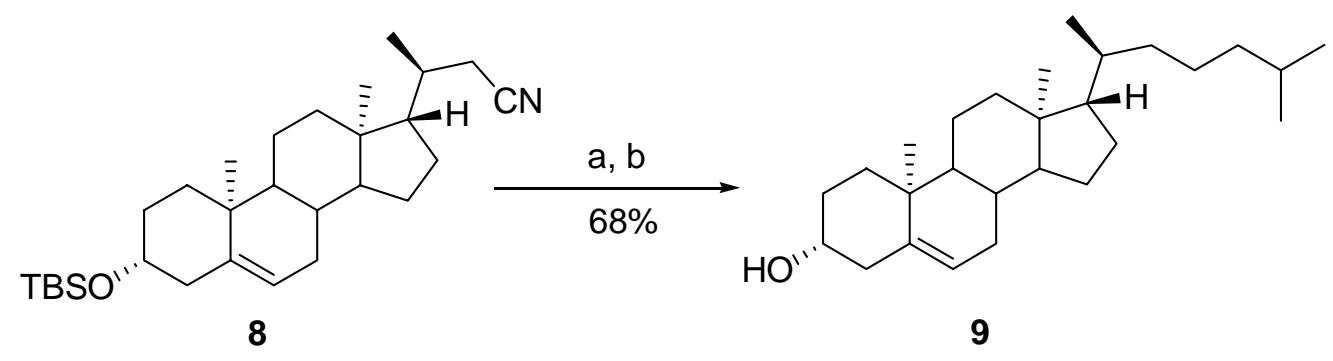

(a) LDA, THF, $-78{ }^{\circ} \mathrm{C} ; \mathrm{BrCH}_{2} \mathrm{CH}_{2} \mathrm{CH}\left(\mathrm{CH}_{3}\right)_{2}$.

(b) (i) $\mathrm{K}$, dicyclohexyl-18-crown-6, toluene, $5.5 \mathrm{~h}$.; (ii) $\mathrm{Bu}_{4} \mathrm{NF}, \mathrm{THF}$.

\section{Scheme 5}

The cyano group appears to be a good activating group for dienophiles like 4,4disubstituted 2-cyano-2,5-cyclohexadienones. Lithium naphthalenide was used as electron donor to remove the cyano group of Diels-Alder adducts providing an approach to the angularly substituted cis-decalin system. ${ }^{43}$ Scheme 6 describes the reaction of cyclohexanone $\mathbf{1 0}$ with penta-1,3-diene. The reduction of adduct $\mathbf{1 1}$ with lithium naphthalenide followed by protonation using methanol gives 12.

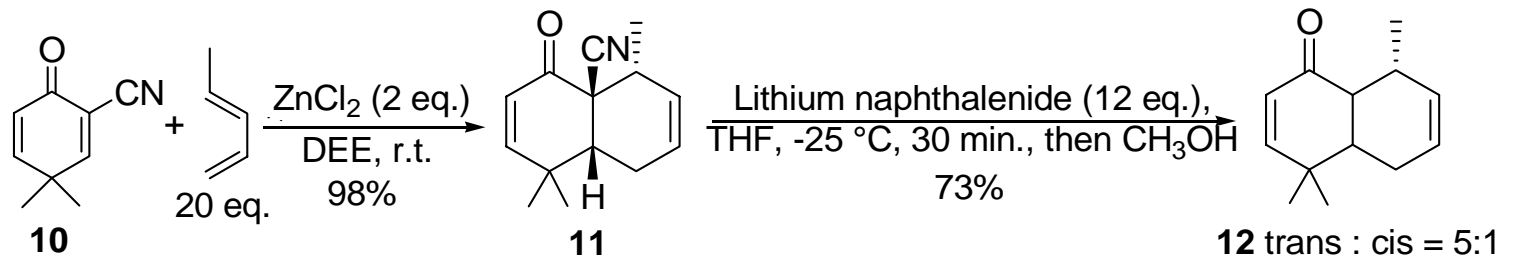

\section{Scheme 6}

It is noteworthy that the ensuring organolithium can be trapped, in the absence of a proton source, by an alkylating agent. In the same way, the reaction of different nitriles with lithium and a catalytic amount of 4,4'-di-tert-butylbiphenyl (LiDBB : lithium di-tert-butylbiphenylide) in THF at low temperature $\left(-30\right.$ or $\left.-78^{\circ} \mathrm{C}\right)$ generates an organolithium intermediate resulting from a reductive decyanation. In the presence of an electrophile (Barbier-type reaction conditions), the coupling product is obtained. ${ }^{44}$ A previous review focused on such non-deprotonating methodologies for obtaining organolithium reagents starting from non-halogenated materials. ${ }^{45}$ Recently Rychnovsky et al. have investigated the reductive spiroannulation of nitriles using LiDBB in THF at low temperatures. ${ }^{46-48}$

The reduction of $\alpha$-aminonitriles with metallic borohydrides leads to decyanation and proceeds through dissociation to iminium and cyanide ions (see section 2-1). Yamada et al. investigated the reductive decyanation of $\alpha$-aminonitriles with sodium in liquid ammonia-THF. ${ }^{49}$ In this case, the hydride reduction was unsuccessful probably due to the failure to form the corresponding iminium ion. The mechanism of decyanation of $\alpha$-aminonitriles with alkali metals 
is probably similar to the one described in Scheme 2 and does not involve an iminium ion. Initial electron transfer leads to a radical anion followed by $\mathrm{C}-\mathrm{CN}$ bond cleavage and formation of a radical. Further reduction of the latter affords an $\alpha$-amino carbanion. ${ }^{50-52}$ Both $\alpha$-amino radicals ${ }^{53}$ and carbanions were trapped by intramolecular cyclisation. ${ }^{54,55}$

Studies have shown that reductive decyanation of $\alpha$-aminonitriles proceeds with retention of configuration $^{56-60}$ or leads to the thermodynamically favored product. ${ }^{52,61}$ The decyanation of $\alpha$-aminonitriles with the $\mathrm{Na} / \mathrm{NH}_{3}$ system was used to perform the decyanation of 2-oxoazetidine4-carbonitriles ${ }^{62}$ or during the asymmetric synthesis of natural ant defense alkaloids. ${ }^{60,63,64}$ Scheme 7 describes the two last steps of the preparation of $(+)$-tetraponerine- 8 15. Alkylation of the $\alpha$-aminonitrile 13 leads to a single isomer 14. The stereoselective decyanation using sodium in liquid ammonia yields exclusively all-cis tetraponerine-8 15.

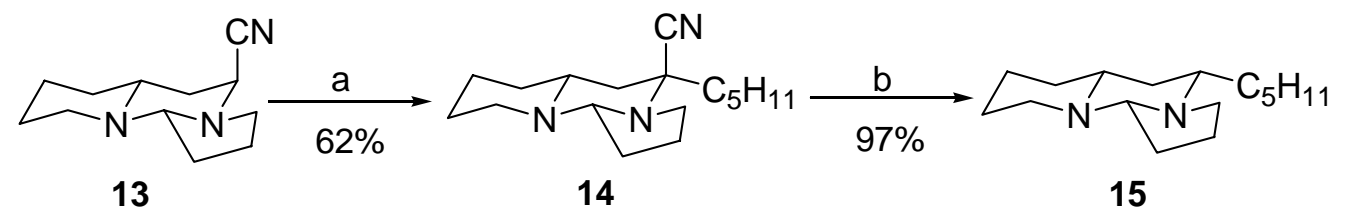

(a) (i) LDA, THF, HMPA, $-78{ }^{\circ} \mathrm{C}$; (ii) $n-\mathrm{C}_{5} \mathrm{H}_{11} \mathrm{Br}$

(b) $\mathrm{Na}, \mathrm{NH}_{3}, \mathrm{THF},-78^{\circ} \mathrm{C}, 20 \mathrm{~min}$.

\section{Scheme 7}

\section{Alumino- and borohydrides}

\section{$2.1 \alpha$-Aminonitriles}

$\alpha$-Aminonitriles are transformed into amino derivatives by reductive decyanation using aluminoand borohydrides. ${ }^{57,65-72}$ The mechanism is a $\mathrm{S}_{\mathrm{N}} 1$ process with formation of an iminium ion followed by an addition of the hydride ion (Scheme 8). ${ }^{73}$ Several facts support this mechanism. The $\mathrm{LiAlD}_{4}$ reduction leads to the $\alpha$-deuterated amine. Formation of the iminium ions favors also the decyanation over the reduction to primary amine. So Lewis acids, such as $\mathrm{AlCl}_{3}$, are able to promote decyanation in unfavorable cases. ${ }^{73}$ Moreover, the decyanation pathway is favored with disubstituted $\alpha$-aminonitriles. ${ }^{74}$

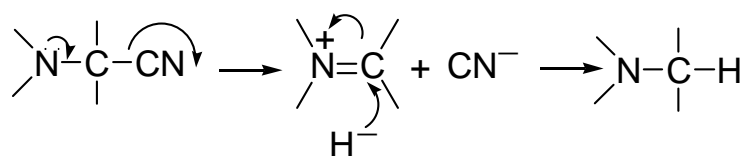

\section{Scheme 8}


The reaction product also depends on the stereoelectronic effects and the strain of the molecule. ${ }^{73,75}$ So the stereoelectronic effects are expected to favor the decyanation process when the nitrile group is antiparallel to the lone-pair electrons of nitrogen. ${ }^{76}$

An anomalous decyanation of monosubstituted nitrile $\mathbf{1 6}$ has been observed (Scheme 9). ${ }^{77}$ Anion 17 is first formed and expels the cyanide ion. The resulting intermediate 18 is then reduced to the decyanation product 19. Excellent yields are obtained. When the $\mathrm{H}$ atom borne by the nitrogen is replaced by a methyl group the expected primary amine is obtained.

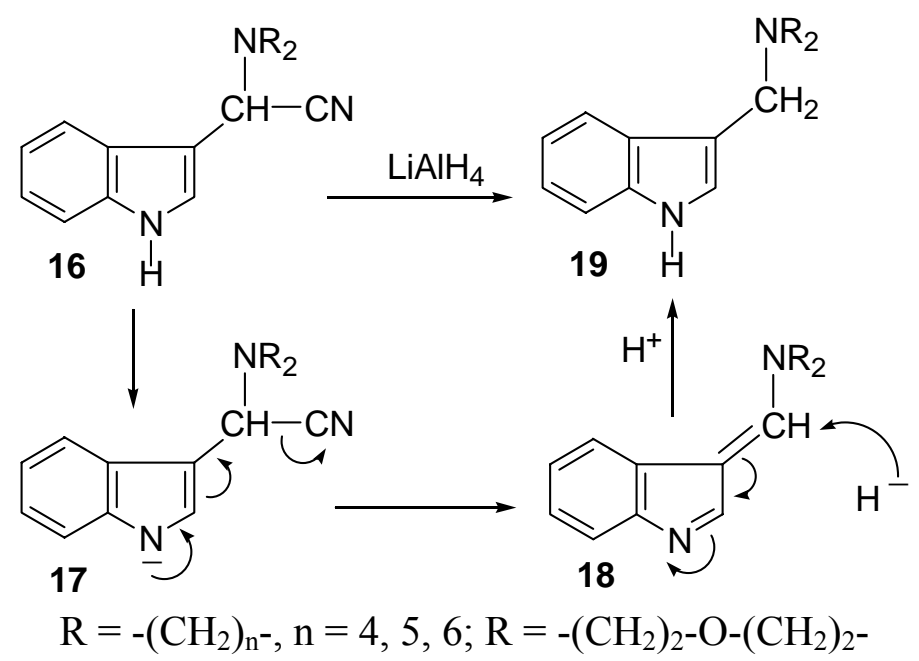

\section{Scheme 9}

Liu and Liang used the Stevens rearrangement for ring enlargement and reductive decyanation to prepare benzazepine derivatives such as $22 .^{78}$ Cyanomethyl quaternary ammonium salt $\mathbf{2 0}$ undergoes ring enlargement and affords $\mathbf{2 1}$ as a mixture of diastereoisomers (syn : trans $=9: 1$ ). They are then reduced with $\mathrm{NaBH}_{4}$ in ethanol to give 22 . 


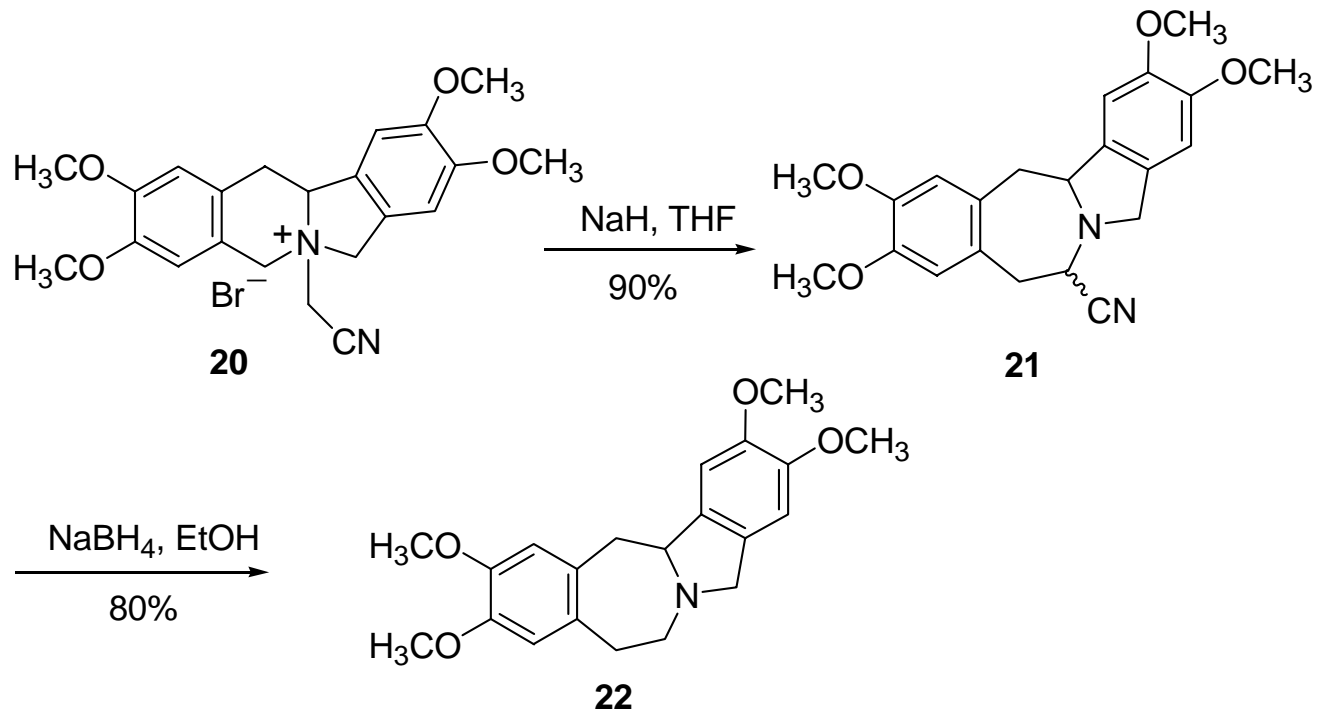

\section{Scheme 10}

$\alpha$-Aminonitriles can also be decyanated with other hydride donors such as $\mathrm{AgBF}_{4} / \mathrm{Zn}\left(\mathrm{BH}_{4}\right)_{2},{ }^{58,79,80} \mathrm{BH}_{3}{ }^{81}$ or $\mathrm{NaBH}_{3} \mathrm{CN} .{ }^{82,83}$ Sassaman used a system containing $\mathrm{NaBH}_{3} \mathrm{CN}$ - $\mathrm{Hg}(\mathrm{TFA})_{2}-\mathrm{DABCO}$ to prepare secondary and tertiary amines from $\alpha$-aminonitriles. $\mathrm{Here} \mathrm{Hg}^{2+}$ ions favor the formation of the iminium intermediate. DABCO decreases the rate of mercury II reduction and prevents polyalkylation of secondary amines. ${ }^{84} \mathrm{Fe}^{2+}$ ions are equally effective in accelerating the elimination of the cyano group in $\alpha$-aminonitriles. They, therefore, promote the reduction with $\mathrm{NaBH}_{3} \mathrm{CN}{ }^{83}$

Amos et al. examined the Diels-Alder reaction of iminoacetonitriles, a class of electrondeficient imines such as 23. The reduction of cycloadduct 24 with $\mathrm{NaBH}_{3} \mathrm{CN}$ affords quinolizidine 25 in a good yield (Scheme 11). ${ }^{85}$

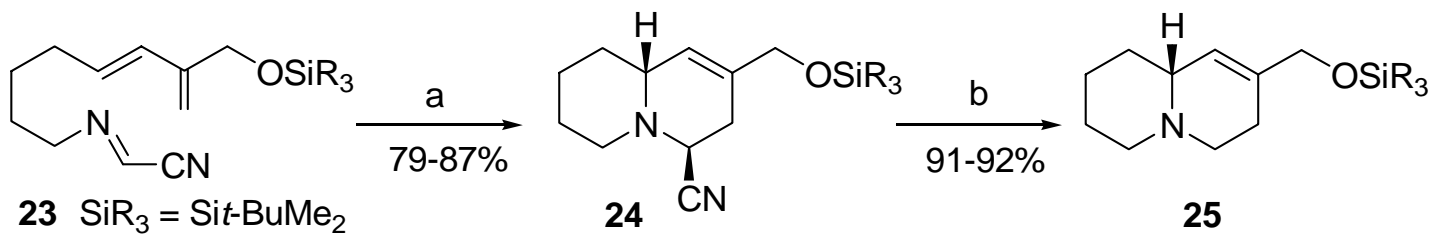

(a) Toluene, $120^{\circ} \mathrm{C}, \mathrm{BHT}$ (3 eq.), $14 \mathrm{~h}$.

(b) $\mathrm{NaBH}_{3} \mathrm{CN}$ (6 eq.), $\mathrm{AcOH}$ (12 eq.), $\mathrm{CH}_{3} \mathrm{CN}$, r.t., 22 h.

\section{Scheme 11}

The reductive decyanation of $\alpha$-aminonitriles by hydrides is stereoelectronically controlled $^{86}$ and proceeds with a high stereoselectivity. ${ }^{58,79,80,87-89}$ For instance the reduction of 
substituted $\alpha$-aminonitrile 26 led exclusively to cyclopenta[c]quinoline derivative 27 (Scheme 12). ${ }^{90}$<smiles>CCN1c2ccccc2[C@@H]2C=CC[C@H]2[C@](C#N)(CC)[C@H]1C</smiles>

26
$\mathrm{NaBH}_{4}, 5$ eq., $\mathrm{MeOH}$ $85 \%$

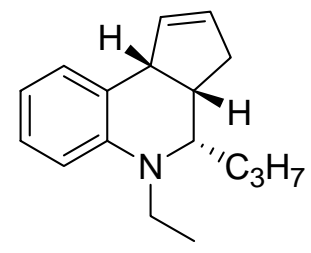

27

\section{Scheme 12}

It is important to notice that $\alpha$-aminonitriles appears as "masked" iminium ions and the reaction of Grignard reagents appears as a valuable method for carbon - carbon bond formation (Bruylants reaction). ${ }^{91}$ This method has been widely used in organic synthesis. ${ }^{63,75,85,88,89}$

\subsection{Other cases}

Alumino- and borohydrides promote reductive decyanation for substrates other than $\alpha$ aminonitriles. Potassium hydride was also described but the yield obtained was poor. ${ }^{92}$ Black and Doyle found that the treatment of 9-allylfluorene-9-carbonitrile 28 and 2,2,4-triphenylpent-3enenitrile 31 with $\mathrm{LiAlH}_{4}$ in $\mathrm{Et}_{2} \mathrm{O}$ (slurry) yield the decyanation product together with the expected amine (Scheme 13).

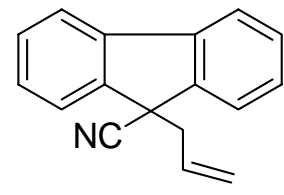

28

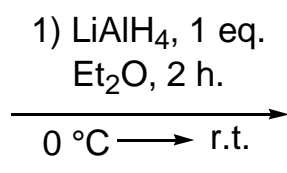

2) $\mathrm{H}_{2} \mathrm{O}$

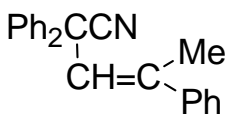

31

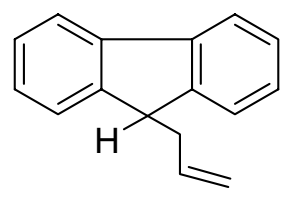

$29(56 \%)$

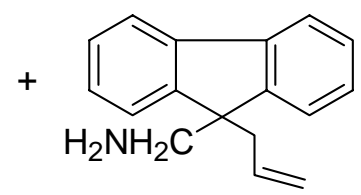

$30(31 \%)$<smiles>C=CCC(C#N)(c1ccccc1)c1ccccc1</smiles>

32

\section{Scheme 13}

In contrast, no decyanation was observed in reactions of 2,2-diphenylpent-4-enenitrile 32 and similar compounds. ${ }^{93}$ The authors proposed an attack on the cyano group followed by elimination of a "hydrogen cyanide complex" and formation of a carbanion : the nitriles yielding the decyanation product are usually precursors of the most stabilized carbanions. No mechanism was proposed, ${ }^{93}$ Scheme 14 could account for the reported products: 


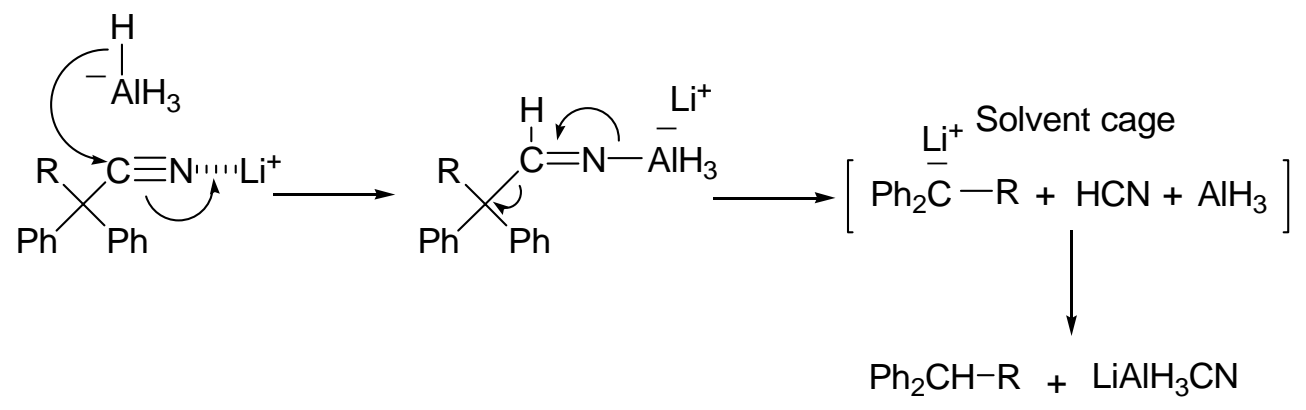

\section{Scheme 14}

We investigated the $\mathrm{LiAlH}_{4}$ reduction of 2,2-diphenylpropionitrile 33 (Scheme 15). ${ }^{94}$ The solvents THF or HMPA favor the decyanation process in comparison with $\mathrm{Et}_{2} \mathrm{O}$. We suggested that, in $\mathrm{Et}_{2} \mathrm{O}$, the imine salt intermediate is stabilized by the cation $\mathrm{Li}^{+}$while in more basic and dissociative medium the $\mathrm{C}-\mathrm{C}$ bond cleavage is favored. The $\mathrm{LiAlD}_{4}$ reduction leads to the deuterated hydrocarbon and could be consistent with an "internal" protonation in a solvent cage. There was no evidence for radical intermediates in this reaction. We deduced that our observations were consistent with the mechanism proposed by Black and Doyle. However a $S_{N}$ pathway cannot be totally excluded since carbon atoms bearing two or three aryl groups exhibit a great reactivity toward the $\mathrm{S}_{\mathrm{N}} 1$ and $\mathrm{S}_{\mathrm{N}} 2$ processes. ${ }^{95}$

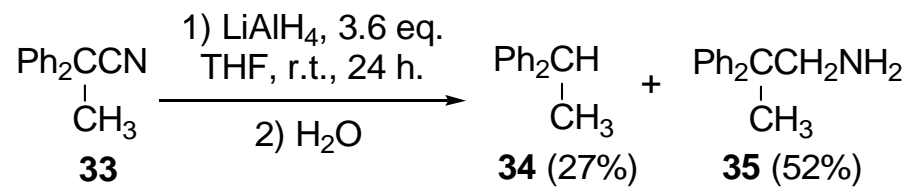

\section{Scheme 15}

An anomalous reduction of $\alpha$-tosyloxy- $\alpha$-(trifluoromethyl)phenylacetonitrile 36 with $\mathrm{NaBH}_{4}$ in DMSO was described by Németh et al. ${ }^{96}$ Since $\mathrm{S}_{\mathrm{N}}$ was disfavored by steric $\left(\mathrm{S}_{\mathrm{N}} 2\right)$ and electronic $\left(\mathrm{S}_{\mathrm{N}} 1\right)$ factors, the authors proposed a single electron-transfer (SET) process (Scheme $16)$.

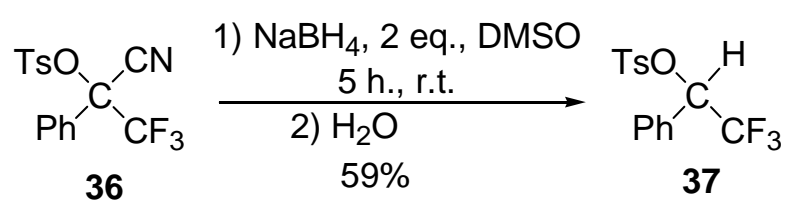

\section{Scheme 16}

In 1991 we described the first experimental evidence for C-C bond cleavage of a $\alpha$ sulfonitrile induced by $\mathrm{LiAlH}_{4}$ in ${ }^{\text {THF }}$ (slurry). ${ }^{7}$ Starting from 2- 
(isopropylsulfonyl)bicyclo[2.2.1]hept-5-ene-2-carbonitrile 38, a mixture of the expected amine 39 and the decyanated product 40 was obtained in an approximate 1-1 ratio (Scheme 17). The mass balance was $88 \%$. The stereochemical outcome of this reaction was uncertain since inconsistent results were obtained from this point of view.

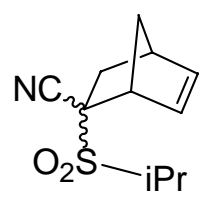

38

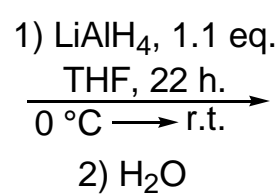

2) $\mathrm{H}_{2} \mathrm{O}$

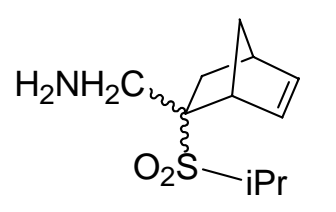

39

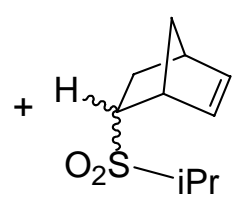

40

\section{Scheme 17}

Later, experiments based on a free radical-clock and isotopic labelling suggested the intervention of radical intermediates. ${ }^{97}$ Electrochemical data were not consistent with an electron transfer from the hydride $\left(\mathrm{E}_{\mathrm{H}^{\circ} / \mathrm{H}^{-}}^{\circ} \approx-0.2 \mathrm{~V} v \mathrm{NHE}\right)$ to the nitrile $38\left(\mathrm{E}_{\mathrm{p}}<-1.96 \mathrm{~V} v s \mathrm{NHE}\right.$ for 38). We realized, however, that this kind of trapping experiment, performed in heterogeneous medium, was not compelling. Independently, Ashby studied the hydride reduction of hindered alkyl iodides. He concluded that unfiltered heterogenous solutions of $\mathrm{LiAlH}_{4}$ or $\mathrm{LiAlD}_{4}$ lead to inconsistent results. ${ }^{98} \mathrm{We}$ are now working on a series of substituted 2-phenylsulfonylnitriles in order to obtain a better reproducibility.

The mechanism of the reductive decyanation promoted by $\mathrm{LiAlH}_{4}$ for substrates other than $\alpha$-aminonitriles remains a puzzle. Different pathways have been proposed depending on the nature of the substrate. It is noteworthy that all substrates undergoing the decyanation reaction are $\alpha$-substituted by a carbanion stabilizing group. The addition-elimination process first proposed by Black and Doyle would be similar to the mechanism proposed for reductive decyanation induced by the hydroxide ion or organometallic reagents (see sections 3 and 5-1).

\section{Acid or base promoted decyanation reactions}

The decyanation reaction is also observed under harsh conditions. Old methods describe sodamide in boiling toluene ${ }^{99}$ or polyphosphoric acid at $200{ }^{\circ} \mathrm{C} .{ }^{100}$ Berkoff et al. have developed the reductive decyanation of sufficiently activated tertiary and secondary nitriles using alkali fusion $\left(150{ }^{\circ} \mathrm{C}, \mathrm{KOH} 85 \%, 4\right.$ eq.). ${ }^{101}$ They proposed a process involving the initial attack of hydroxide ion on the nitrile carbon followed by a C-C bond cleavage. Trapping of potassium cyanate supports this mechanism (Scheme 18). 


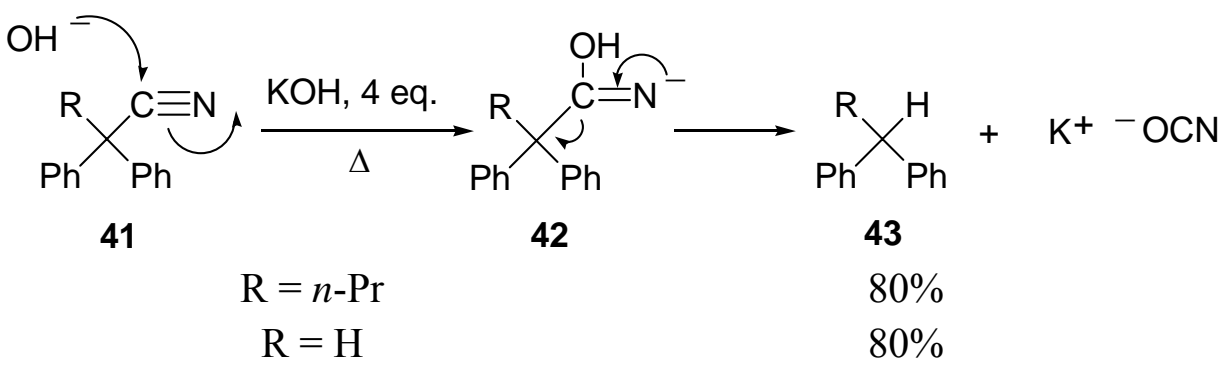

\section{Scheme 18}

More recently, Bendale et al. reported the reductive decyanation of alkyldiphenylacetonitriles using sodium hydroxide-PEGs in a domestic microwave oven. ${ }^{102}$ PEGs exhibit a crown ether role by complexing $\mathrm{Na}^{+}$and with microwave irradiation high yields are obtained in just 2-3 minutes. The mechanism proposed was similar to that described by Berkoff. Using this methodology 4,4-diphenylbutylamines 46, reported to be antilipidperoxidative, neuroleptic and antihypertensive agents, were prepared. Nitriles $\mathbf{4 4}$ are obtained from diphenylacetonitrile by alkylation under phase transfer catalysis conditions (PTC). The next step is the substitution of the remaining halogen atom by a secondary amine leading to 45 (Scheme 19).

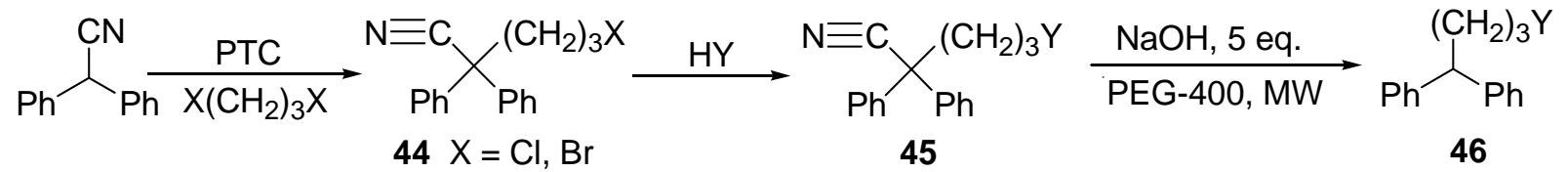

$\begin{array}{ll}\text { sec. } \text { Amine }=\text { YH } & \text { Yield }(\%) \\ \text { N-Phenylpiperazine } & 68 \\ \text { N-Methylpiperazine } & 71 \\ \text { Morpholine } & 81 \\ \text { Pyrrolidine } & 65 \\ \text { Piperidine } & 72\end{array}$

\section{Scheme 19}

Milart et al. prepared a series of di- or triamino-m-terphenyls as described in Scheme 20. Gewald's method was applied for the preparation of 47. ${ }^{103}$ The cyano groups were removed from 47 under harsh basic conditions. The authors consider that treatment with ethanolic sodium hydroxyde solution at high pressure $(2.5 \mathrm{MPa})$ and temperature $\left(220^{\circ} \mathrm{C}\right)$ may cause the conversion of the nitrile groups to anions of the corresponding carboxylic acids (48) which easily decarboxylate. ${ }^{103}$ 


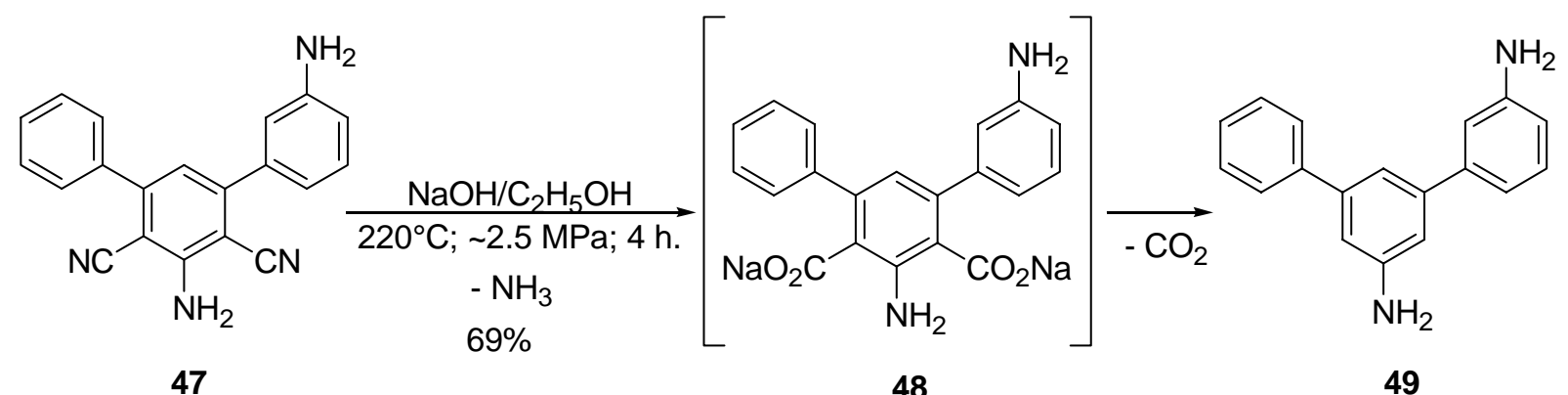

\section{Scheme 20}

Under severe acidic conditions, the reductive decyanation is equally observed with good yields. ${ }^{104}$ The nitrile group is probably hydrolyzed and then decarboxylated. Such conditions have been employed in the course of the synthesis of benzo[b]thiophenes. The method is described in Scheme 21. Benzoannelation is developed via conjugate addition-displacement on $\beta, \beta$-(dimethylthio)ketone $\mathbf{5 0}$ by carbanion derived from 2-cyanomethylthiophene and is followed by acid induced cyclisation of $\mathbf{5 1}$. The nitrile group is efficiently removed using a mixture of sulfuric acid, acetic acid and water at $180{ }^{\circ} \mathrm{C}$ (Scheme 21$)$.
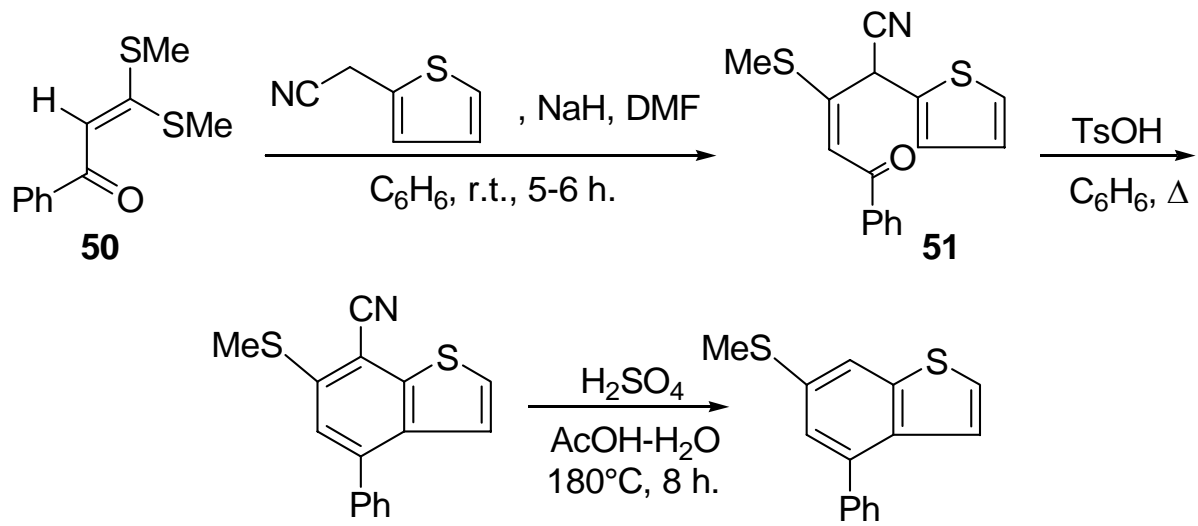

$5272 \%$

53

\section{Scheme 21}

Sheverdov et al. managed to reduce selectively one cyano group in position 2 of tetracyanocyclohexanones 54. This reaction is explained by intramolecular interaction of the cyano group with the carbonyl group. On heating with $5 \% \mathrm{H}_{2} \mathrm{SO}_{4}$, hydroxy compounds 55 were isolated. More severe conditions $\left(30 \% \mathrm{H}_{2} \mathrm{SO}_{4}\right)$ led to the formation of tricyanocyclohexanones 58. Intermediates $\mathbf{5 6}$ are formed by retro-cyclisation of $\mathbf{5 5}$. Hydrolysis of amides $\mathbf{5 6}$ and subsequent decarboxylation of the corresponding carboxylic acids would lead to the final products (Scheme 22). ${ }^{105}$ 
<smiles>[R]C1C(=O)CC(C)(C#N)C(C#N)(C#N)C1[Al]</smiles>

54

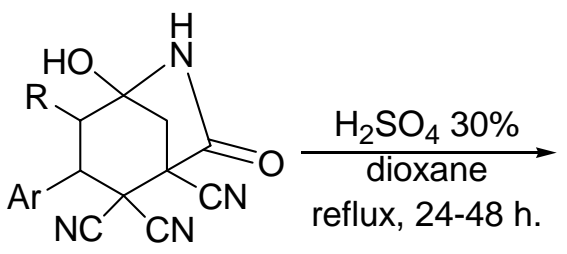

55<smiles>[R]C1C(=O)CC(C#N)(C(N)=O)C(C#N)(C#N)C1[Hg]</smiles>

56

$\mathrm{R}$

$-\mathrm{CH}_{3}$

$\mathrm{CH}_{3}\left(\mathrm{CH}_{2}\right)_{2-}$

$-\mathrm{CH}_{3}$

$\mathrm{CH}_{3}\left(\mathrm{CH}_{2}\right)_{2-}$<smiles>[R]C1C(=O)CC(C#N)(C(=O)O)C(C#N)(C#[Al])C1[Al]</smiles>

57<smiles>[R]C1C(=O)CC(C#N)(C#N)C([Al])(C#N)C1[Te]O</smiles>

58
Ar

$\mathrm{Ph}$

$\mathrm{Ph}$

$\mathrm{MeOC}_{6} \mathrm{H}_{4}-$

$\mathrm{MeOC}_{6} \mathrm{H}_{4-}$
Yield (from 54 or 55)

$76 \%$

$81 \%$

$79 \%$

$71 \%$

\section{Scheme 22}

Satoh et al. synthesized chiral 4,4-disubstituted-2-cyclopentenones ${ }^{106}$ and elaborated a six step synthesis for enantiomerically pure $(+)$ - $\alpha$-Cuparenone 63. They investigated the reaction of cyanomethyllithium with optically active sulfoxide $\mathbf{5 9}$ and obtained enaminonitrile $\mathbf{6 0}$. The latter is treated under reflux optimally with phosphoric acid in acetic acid, containing a small amount of water, to afford the decyanated compound 62 with 93\% yield and over 99\% ee (Scheme 23).

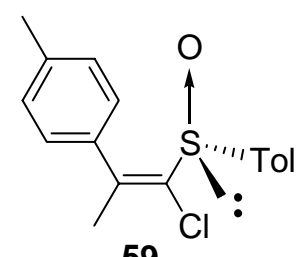

59

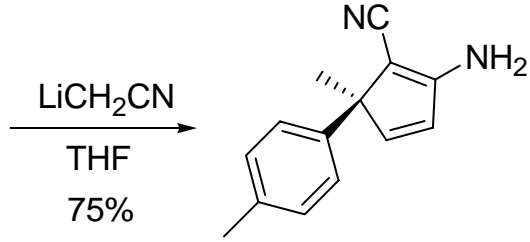

60<smiles>Cc1ccc([C@]2(C)C=CC(N)=C2C#N)cc1</smiles>

Scheme 23 
Alexandre et al. prepared thiazoloquinazolinones derivatives such as 65. In the last step, they heat the precursor 64 in $\mathrm{H}_{2} \mathrm{SO}_{4}$ with a focused microwave reactor. The transformation involves deprotection of the nitrogen group and decyanation of the thiazole moiety (Scheme 24). ${ }^{107}$

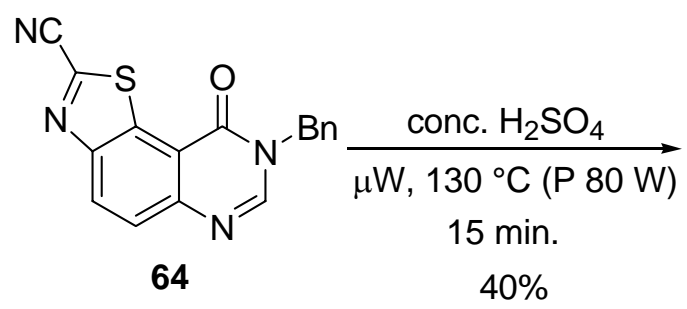<smiles>O=c1[nH]cnc2ccc3ncsc3c12</smiles>

65

\section{Scheme 24}

\section{4. $\mathrm{Bu}_{3} \mathrm{SnH}$ or $\mathrm{SmI}_{2}$ promoted decyanation reactions}

Curran and Seong discovered accidentally that mono- and dialkylated malonitriles (geminal dinitriles) are reductively decyanated to mononitriles on treatment with tributyltin hyride and a small amount of AIBN in refluxing benzene. ${ }^{108}$ They proposed a chain mechanism to account for this reduction, the first step being the addition of the tin radical to the carbon-nitrogen triple bond to generate a carbon radical species (Scheme 25). So far, the reaction is limited to geminal dinitriles. Attempts to reduce 2-cyanoacetate under the same conditions gave no reaction. The first radical adduct is apparently generated, but its fragmentation is not fast enough with respect to the reverse addition to propagate the chain. Thus, the fragmentation of the carbon-carbon bond is facilitated by the ability of the nitrile group to labilize adjacent bonds.

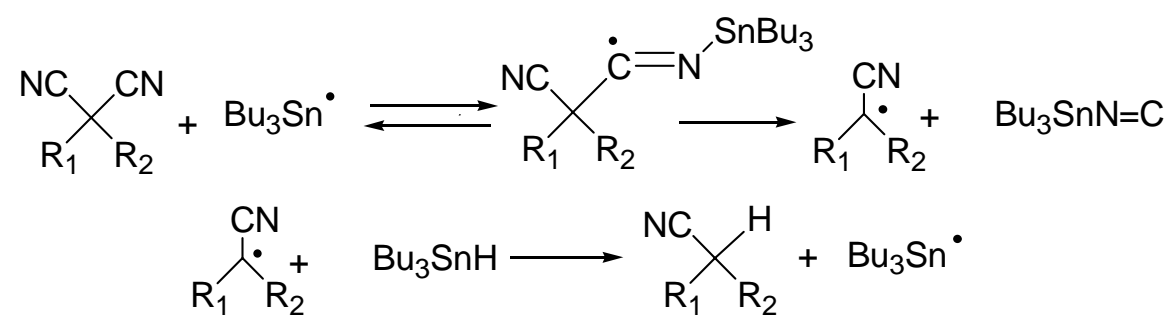

\section{Scheme 25}

A variety of mono- and dialkylated malonitriles were reduced with good yields (75-94\%) in this way. The $\alpha$-nitrile radical was trapped by cyclization using the 5-hexenyl rearrangement. The rate constant of cyclization of the unsubstituted 5-hexenyl radical is k $=210^{5} \mathrm{~s}^{-1}$ at $20{ }^{\circ} \mathrm{C}$. Substitution of the radical with the cyano group should decrease this constant of approximately 
two orders of magnitude. ${ }^{109}$ When $\mathbf{6 6}$ is reduced, the cyclized product $\mathbf{6 8}$ is formed together with 67 (Scheme 26).

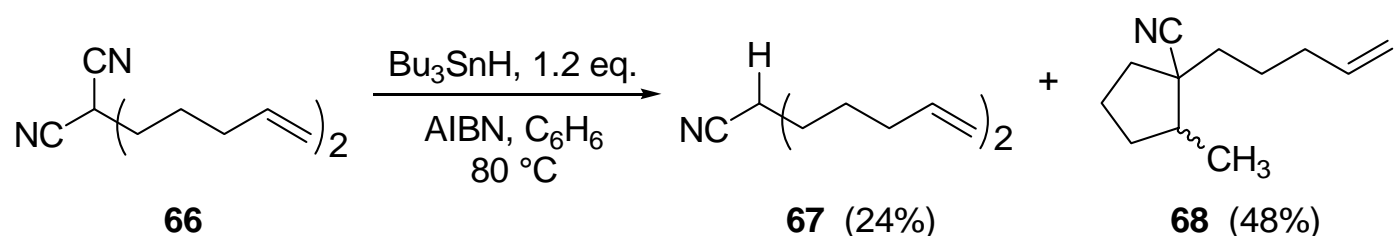

\section{Scheme 26}

Gerlach developed the synthesis of tricyclic cyano substituted tetrahydroquinolines $\mathbf{7 0}$ in good yields from the geminal dinitriles $\mathbf{6 9}^{110}$ by radical decyanation using $\mathrm{Bu}_{3} \mathrm{SnH}$ (Scheme 27).<smiles>[Y]C1CCN2c3ccccc3CC(C#N)(C#N)C12</smiles>

69 $\mathrm{X}$ $-$ $-\mathrm{CH}_{2}$ $-\mathrm{NMe}$

$\mathrm{O}$ $\mathrm{SO}_{2}$<smiles>[X]CC1C(C#N)Cc2ccccc2N1CC</smiles>

70

Yield (\%)

75

78

97

99

\section{Scheme 27}

Hattori and Grossman used this method to prepare the fused bicyclic $\alpha$-amino acid $\mathbf{7 4}$ that lacked a quaternary center at the ring junction. ${ }^{111}$ Tethered diacid 71 undergoes a double Michael addition with the alkynone and affords 72. This cyclic geminal dinitrile was treated with tributyltin hydride to afford mononitrile 73 in 59\% yield (5:1 mixture of diastereomers, Scheme 28). The reaction of the intermediate decyanated radical with tributyltin hydride apparently occurred predominantly from the less hindered face to give the higher energy cis isomer of the product. 


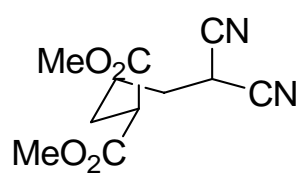

71

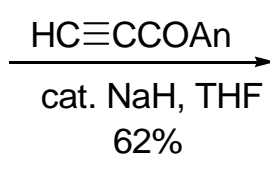

$62 \%$

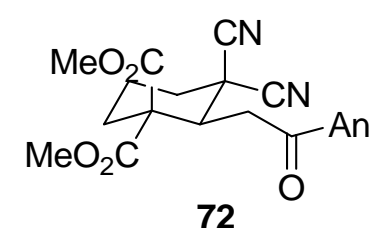

72

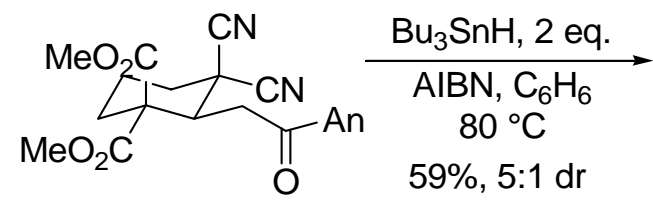

72

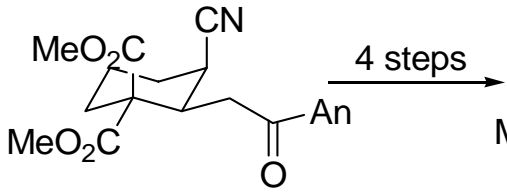

73

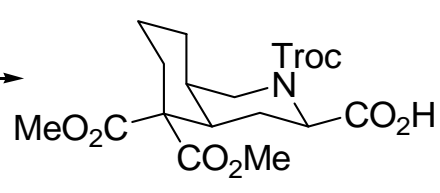

74

An $=p$-anisyl

Troc $=$ 2,2,2-trichloroethoxycarbonyl

\section{Scheme 28}

It is worth noting that the reductive decyanation on mononitrile 75 promoted by tributyltin hydride proposed by Rychnovsky and Swenson is, in fact, a nitrile transfer reaction. ${ }^{12}$ The reaction proceeds by a mechanism of cyclization followed by $\beta$-scission affording the $1,4-$ or 1,5-cyano transfer, when $n=1,2$, respectively (formation of 77). When the cyclization is not allowed $(\mathrm{n}=0,3)$, the nitrile transfer reaction is not observed and the simple dehalogenation products 76 are formed (Scheme 29). 


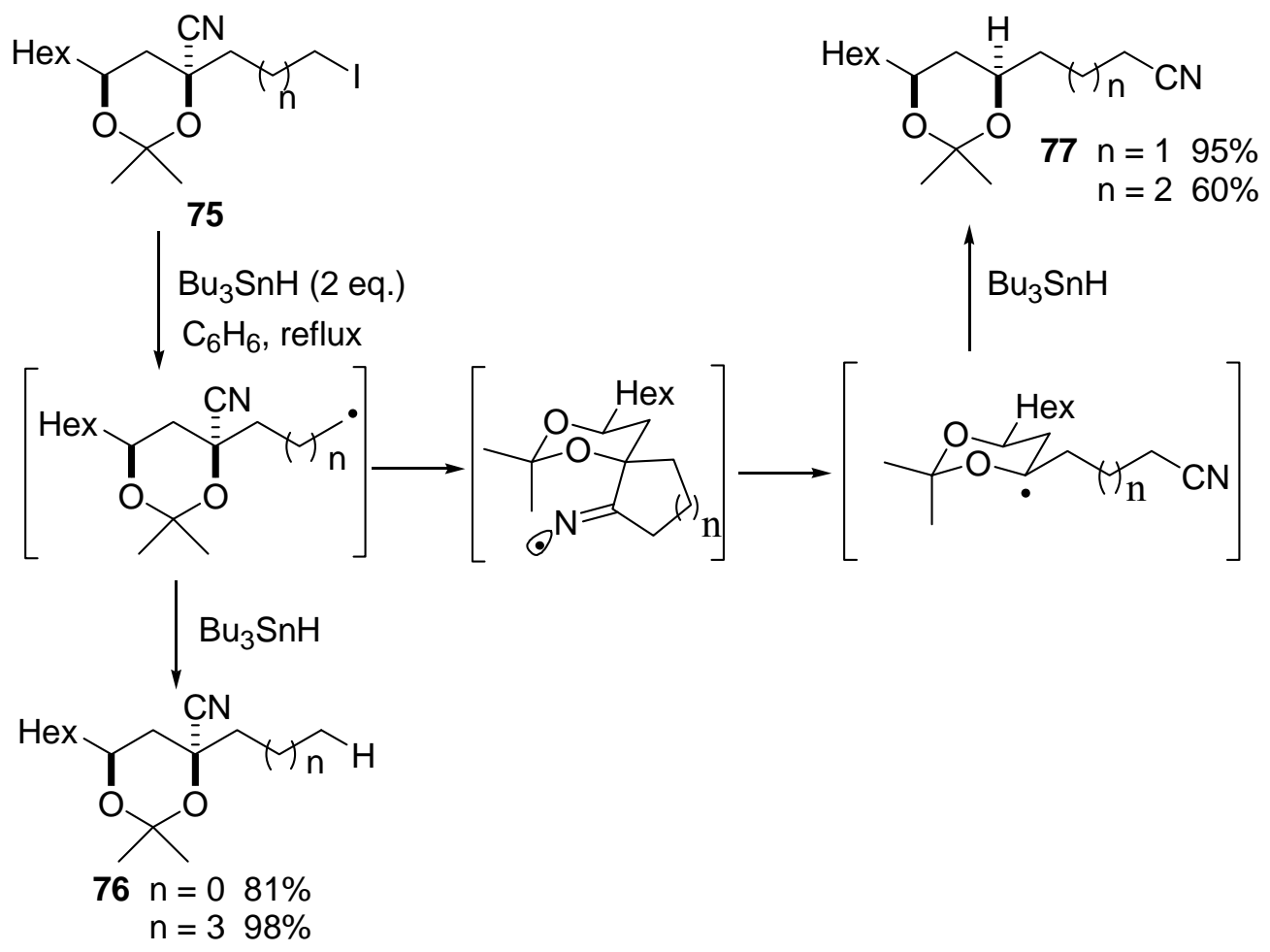

\section{Scheme 29}

Kang et al. proposed an alternative samarium (II) iodide (2-3 eq., in THF/HMPA, 5-10\% $\mathrm{v} / \mathrm{v}$ versus THF, $0^{\circ} \mathrm{C}$ ) promoted reductive decyanation of malonitriles. ${ }^{113,114}$ Whithout HMPA no decyanation reaction was observed. The reaction was successfully applied to $\alpha$-ethoxycarbonyl substituted nitriles at room temperature and extended to a range of substrates with an hydroxyl group or a carbon-carbon double bond located on the side chain (Scheme 30, entries 1-7). The mechanism could be similar to the tin hydride method, however, no cyclization products were observed when the side chain has a $\mathrm{C}=\mathrm{C}$ bond. 


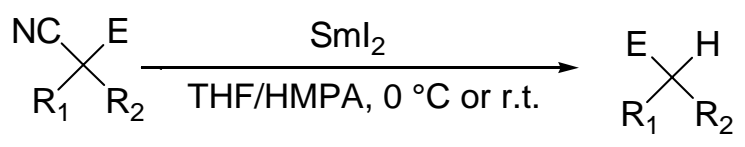

78

$$
\mathrm{E} \text { (entry) }
$$

$-\mathrm{CN}(1)$

$-\mathrm{CN}(2)$

$-\mathrm{CN}(3)$

$-\mathrm{CO}_{2} \mathrm{Et}(4)$

$-\mathrm{CO}_{2} \mathrm{Et}(5)$

$-\mathrm{CO}_{2} \mathrm{Et}(6)$

$-\mathrm{CO}_{2} \mathrm{Et}(7)$

$-\mathrm{CO}_{2} \mathrm{Et}(8)$

$-\mathrm{CO}_{2} \mathrm{Et}(9)$

$-\mathrm{CO}_{2} \mathrm{Et}(10)$

$-\mathrm{CO}_{2} \mathrm{Et}(11)$

\begin{abstract}
$\mathrm{R}^{1}$
\end{abstract}
$\mathrm{C}_{6} \mathrm{H}_{5} \mathrm{CH}_{2}-$

$\mathrm{C}_{6} \mathrm{H}_{5} \mathrm{CH}_{2-}$

$\mathrm{CH}_{2}=\mathrm{CH}\left(\mathrm{CH}_{2}\right)_{3}-$

$\mathrm{C}_{6} \mathrm{H}_{5} \mathrm{CH}_{2}-$

$\mathrm{C}_{6} \mathrm{H}_{5} \mathrm{CH}_{2}-$

$\mathrm{CH}_{2}=\mathrm{CH}\left(\mathrm{CH}_{2}\right)_{3}-$

$\mathrm{HO}\left(\mathrm{CH}_{2}\right)_{6}{ }^{-}$

$\mathrm{C}_{7} \mathrm{H}_{15-}$

$\mathrm{C}_{7} \mathrm{H}_{15-}$

$\mathrm{C}_{7} \mathrm{H}_{15-}$

$\mathrm{C}_{7} \mathrm{H}_{15-}$
79

$\mathrm{R}^{2}$

$\mathrm{H}$

$\mathrm{C}_{6} \mathrm{H}_{5} \mathrm{CH}_{2-}$

$\mathrm{H}$

$\mathrm{H}$

$\mathrm{C}_{6} \mathrm{H}_{5} \mathrm{CH}_{2-}$

$\mathrm{CH}_{2}=\mathrm{CH}\left(\mathrm{CH}_{2}\right)_{3}-$

$\mathrm{H}$

$\mathrm{EtCO}_{2}\left(\mathrm{CH}_{2}\right)_{2-} \quad 75$

$\mathrm{CN}\left(\mathrm{CH}_{2}\right)_{3-} \quad 85$

$\mathrm{Et}_{2} \mathrm{NCO}\left(\mathrm{CH}_{2}\right)_{2-} \quad 88$

$\mathrm{Cl}\left(\mathrm{CH}_{2}\right)_{4}-$
Yield(\%)

85

97

53

54

87

87

49

61

\section{Scheme 30}

With this method, Molander and Wolfe reduced also a serie of $\alpha$-cyano esters and show that nitriles, amides and chlorides are well-tolerated (Scheme 30, entries 8-11). The reaction conditions were similar to these described by Kang (two equivalents of ethanol were added). ${ }^{115}$

In a review, Kamochi and Kudo described the rapid reduction of a variety of organic functionalities including decyanation with $\mathrm{SmI}_{2}{ }^{116}$

\section{Miscellaneous}

\subsection{Organometallic promoted decyanation reactions}

There are literature reports on the decyanation of tertiary nitriles by organometallic reagents. ${ }^{117,118}$ In 1953, Blicke and Tsao studied the action of several Grignard reagents on nitriles. ${ }^{119}$ Diphenylacetonitrile reacts with ethylmagnesium bromide in refluxing toluene giving the evolution of about one equivalent of ethane. After acid hydrolysis, 1,1-diphenyl-2-butanone $(20 \%)$ and diphenylmethane (45\%) were found. When the reaction mixture was carbonated, diphenylmalonic acid (55\%) was found together with 1,1-diphenyl-2-butanone (5\%). The nitriles were difficult to isolate but propionic acid was isolated after hydrolysis. Similar results were obtained with other Grignard reagents but the yield of diphenylmethane was much lower. The reaction scheme 31 may explain the formed products. The first step seems to be a nucleophilic addition of the Grignard reagent on the nitrile group, followed by the elimination of propionitrile and formation of diphenylmethylmagnesium bromide. The same process can occur after an initial deprotonation of diphenylacetonitrile. 


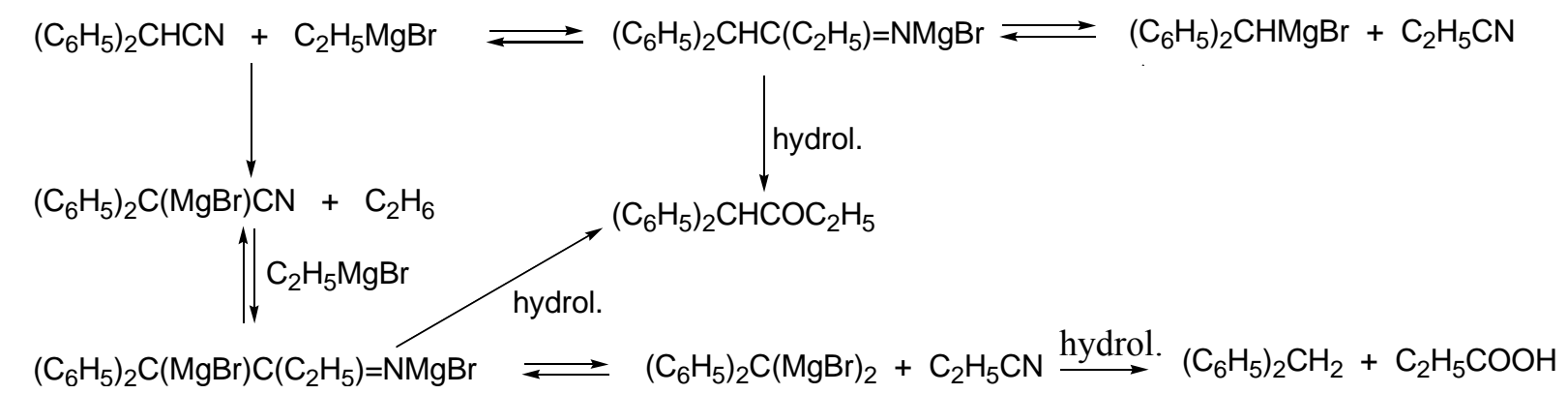

\section{Scheme 31}

King et al., studying the decyanation of 9-cyanofluorenes promoted by ethylmagnesium bromide in refluxing xylene, proposed a simple general $\mathrm{S}_{\mathrm{N}} 2$ mechanism to this reaction. ${ }^{120}$

Kulp and Romanelli extended this method to alkyldiphenylacetonitriles and formed decyanation products using either methyllithium or phenyllithium as reagents. ${ }^{121}$ They also observed the formation of the decyanation product when treating butyldiphenylacetonitrile with phenylmagnesium bromide at a reaction temperature rising to $180^{\circ} \mathrm{C}$.

During the synthesis of imidazoles next to a quaternary carbon center, Gregory et al. treated tertiary nitriles $\mathbf{8 0}$ by methylmagnesium bromide and obtained the desired ketone. But when alkyllithiums in ether solvents were tried as an alternative to Grignard reagents, both ketone and decyanation product 82 were obtained. With methyllithium or butyllithium, in THF, yields of decyanation are quantitative. ${ }^{122}$ The authors explained the formation of decyanation products through a 4-membered transition state 81, the collapse of which is accompanied by a hydride ion abstraction from the alkyl substituent $\mathrm{R}$ by the incipient benzylic carbonium ion at the 1-position of the tetrahydronaphthalene nucleus (Scheme 32). The formation of a monodeuterated compound as the sole decyanation product in an experiment with $\mathrm{CD}_{3} \mathrm{Li}$, but not when the reaction was quenched in THF with $\mathrm{DCl}$ supports this mechanism. Formation and fragmentation of a 4-centered transition state in THF probably occurs because THF is a stronger Lewis base than diethyl ether or benzene and is better to solvate the lithium cation. Marr et al. proposed a similar mechanism for decyanation of ferrocenyl- $\alpha, \alpha$-dibenzylmethylcyanide induced by $n$-BuLi. ${ }^{117}$ An electron transfer pathway was also proposed for this kind of decyanation. $^{123}$ 


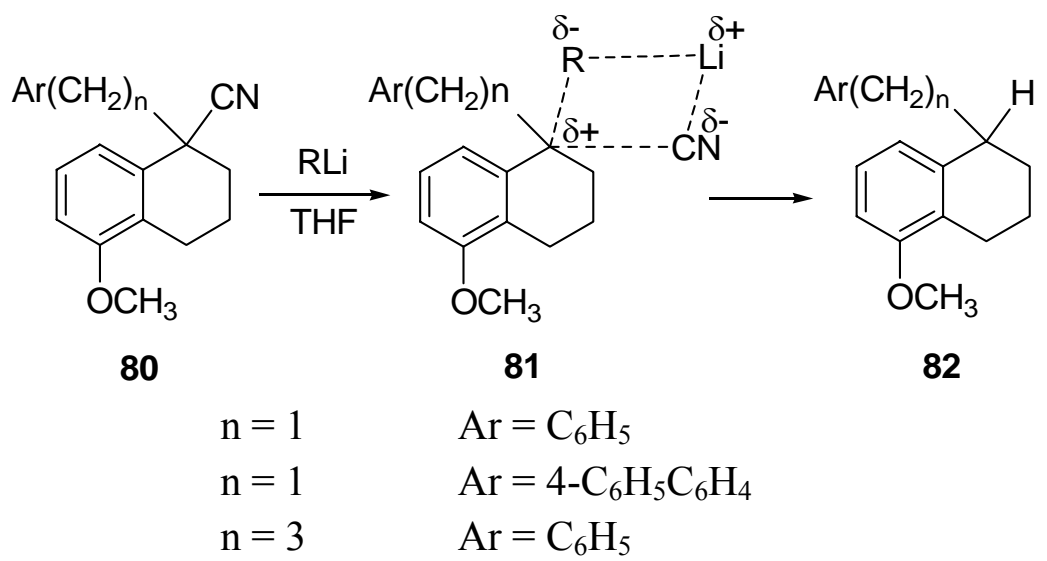

\section{Scheme 32}

\subsection{Sodium dithionite promoted decyanation reactions}

Uridine 84 was prepared in high yield from 5-cyanouridine 83 by the action of sodium dithionite in aqueous sodium hydrogen carbonate. The reaction presumably involves initial reduction of 83 into 85 followed by a base catalysed elimination of hydrogen cyanide (Scheme 33). ${ }^{124}$ Similar conditions were used for the decyanation of a pyrazinecarbonitrile but the reaction was not entirely reliable. ${ }^{125}$<smiles>CC1(C)OC2C3OC(C2O1)C(n1cc(C#N)c(=O)[nH]c1=O)O3</smiles>

83

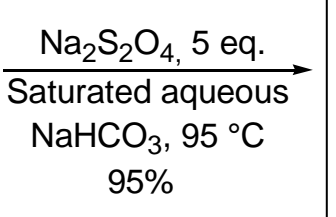

$95 \%$

\section{Scheme 33}

\subsection{Raney nickel or hydrogenation promoted decyanation reactions}

A Raney nickel mediated decyanation was used to modify piperidine scaffolds containing the chiral, non racemic $N$-(cyanomethyl)oxazolidine system. Alkylation of the commercialy available $\mathbf{8 6}$ is followed by treatment with Raney nickel. ${ }^{126,127}$ Compounds $\mathbf{8 8}$ are obtained as a mixture of two epimers at the C-6 position without any racemisation at the C-2 methyl group. The authors proposed the formation of a prochiral iminium ion which could be explained in terms of a "push pull" mechanism. The delivery of the hydrogen present in Raney nickel is the result of a stereoelectronically controlled process. ${ }^{86}$ The oxazolidine epimerization probably occurs during workup of the reaction mixture. 


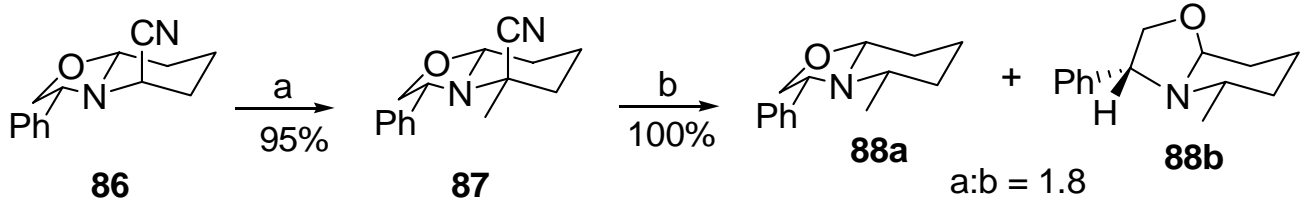

(a) (i) LDA (3 eq.), THF, $-78^{\circ} \mathrm{C}, 20$ min. (ii) Mel (2 eq.), $-78^{\circ} \mathrm{C} \longrightarrow$ r.t.

(b) Raney nickel (excess), THF, r.t., $1.5 \mathrm{~h}$.

\section{Scheme 34}

Albaneze-Walker et al. have developed a mild and robust protocol for the deoxygenation/ decyanation of pyrazine carbonitrile- $N$-oxides such as 89. These transformations occur by hydrogenation with platinium on carbon in the presence of activated carbon under acidic conditions. ${ }^{125}$ The generality of this decyanation was explored and good yields were obtained (Scheme 35).

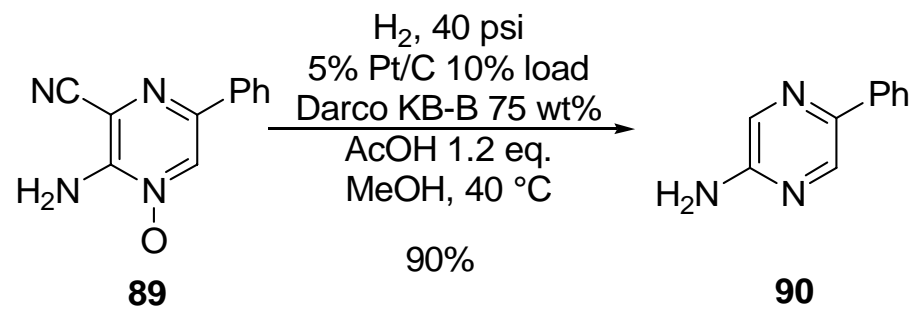

\section{Scheme 35}

\subsection{Hydrolytic decyanation}

The hydrolytic decyanation of $\alpha$-cyano- $\gamma$-lactones 91 with wet alumina in a variety of solvents affords the corresponding $\gamma$-lactones 92. The transformation occurs under neutral conditions and without the need for an aqueous workup. We report here yields obtained in THF with $1.9 \mathrm{~g}$ of alumina per mmol of substrate. The proposed mechanism involves the initial formation of ketenimines which react with water to form successively ketenes and carboxylic acids. The later subsequently decarboxylate to yield $\gamma$-lactones (Scheme 36). ${ }^{128}$ 


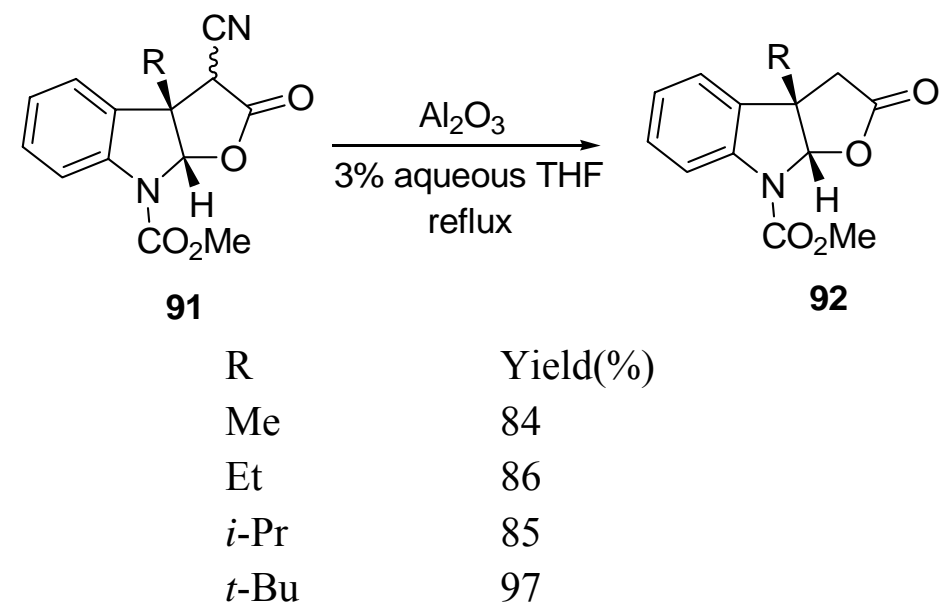

\section{Scheme 36}

\subsection{Electrochemical cleavage of nitriles}

The use of electrochemically generated electrons was first reported in 1968 by Arapakos and Scott. ${ }^{129}$ Decyanation of dehydroabietonitrile, cycloheptyl nitrile and octanenitrile, in anhydrous amine media, produces dehydroabietene, cycloheptane and n-heptane, respectively, in 60-80\% yields. They showed that the electrolytic generation of solvated electrons provides a reductive selectivity with sensitive nitriles and avoids the side reactions encountered with the chemical methods of generating solvated electrons, for example, the competitive reduction of some primary and secondary nitriles to their corresponding amines. This method was used to perform reductive decyanation during the total synthesis of $\left( \pm\right.$ )-Hirsutene 95 (Scheme 37). ${ }^{22}$

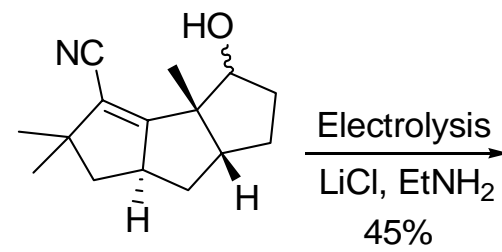

93

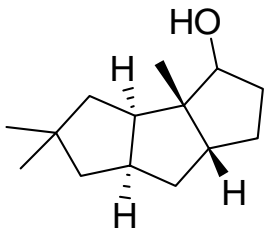

94

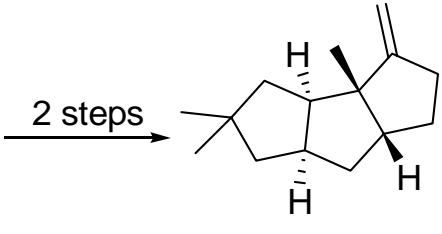

95

\section{Scheme 37}

Shono et al. reported the electroreductive decyanation of a great range of nitriles with a $\mathrm{Zn}$ cathode in DMF containing Et ${ }_{4}$ NOTs as a supporting electrolyte. ${ }^{130}$ The yield of the reaction is highly influenced by electrolytes, electrode material and solvents but the method is applicable to epoxy, $\alpha$-alkoxy or $\alpha$-amino nitriles. As a mechanism, they proposed the dissociation of the radical anion formed by a first electron transfer, the radical formed being reduced by a second electron and then protonated (see Scheme 2, $\mathrm{M}=$ zinc electrode) Nevertheless a two-electron reduction yielding the corresponding dianion was proposed in the electrochemical reduction of benzenedicarbonitriles. ${ }^{131}$ 


\subsection{Transition metals promoted decyanation reactions}

In representative cases, the reductive decyanation of alkyl nitriles was carried out in 58-100\% yields by the action of $\mathrm{Fe}(\mathrm{acac})_{3} \mathrm{Na}$ in benzene at room temperature (acac $=\mathrm{C}_{5} \mathrm{H}_{7} \mathrm{O}_{2}$, acetylacetonato). ${ }^{132}$ More recently, the carbocyclization reaction of $o$-iodophenyl ketones 96 with acrylonitrile in the presence of cobalt catalyst and $\mathrm{Zn}$ power in acetonitrile at $80{ }^{\circ} \mathrm{C}$ afforded indene derivatives 97 in good yields. Interestlingly, no cyano group was present in the formed products (Scheme 38). The reason for this reductive decyanation remains unclear. ${ }^{133}$ The reductive decyanation of a pyrazinecarbonitrile or pyridinecarbonitriles by titanium (III) chloride was also reported. ${ }^{125,134}$

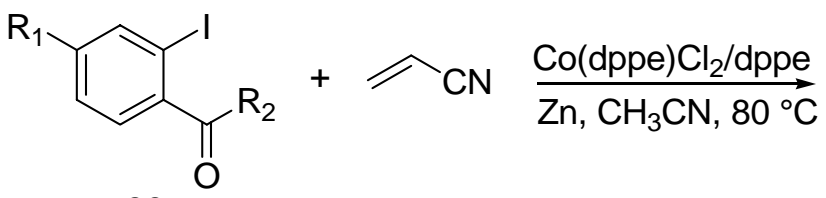

96

$\mathrm{R}_{1}=\mathrm{H} ; \mathrm{R}_{2}=\mathrm{Me}$

$\mathrm{R}_{1}=\mathrm{OMe} ; \mathrm{R}_{2}=n-\mathrm{Bu}$

$\mathrm{R}_{1}=\mathrm{OMe} ; \mathrm{R}_{2}=\mathrm{Ph}$<smiles>[R]C1=CCc2cc([R1])ccc21</smiles>

97

yield $(\%)$

95

85

86

dppe : bis(diphenylphosphino)-ethane

\section{Scheme 38}

\subsection{Photoinduced decyanations}

Photoinduced decyanations lead generally to low yields but show a mechanistic interest. ${ }^{135-138}$ Homma and Yamada reported that irradiation of phenylacetonitrile and its derivatives $\mathbf{9 8}$ in the presence of triethylamine give $\alpha$-benzylated triethylamine 99, bibenzyl 100 and toluene 101 (decyanation product, 16-67\% yields based on the substrate consumed) derivatives (Scheme 39); the formation of these products is explained in terms of a benzylic intermediate radical formed by electron transfer between the triethylamine and the substrate, followed by elimination of a cyanide anion from the radical anion of the starting compound. ${ }^{139}$

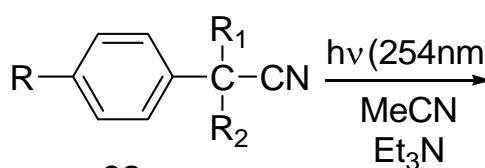

98

$\mathrm{R}=\mathrm{H}, \mathrm{R}_{1}=\mathrm{H}, \mathrm{R}_{2}=\mathrm{H}$

$\mathrm{R}=\mathrm{MeO}, \mathrm{R}_{1}=\mathrm{H}, \mathrm{R}_{2}=\mathrm{H}$

$\mathrm{R}=\mathrm{H}, \mathrm{R}_{1}=\mathrm{Ph}, \mathrm{R}_{2}=\mathrm{H}$

$\mathrm{R}=\mathrm{H}, \mathrm{R}_{1}=\mathrm{Ph}, \mathrm{R}_{2}=\mathrm{Ph}$

Scheme 39

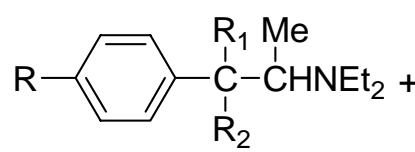

99

$18 \%$

$38 \%$

$26 \%$

$10 \%$

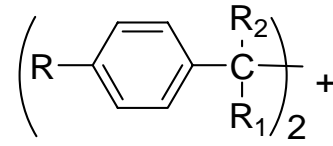

100

$16 \%$

$15 \%$

$7 \%$

$0 \%$

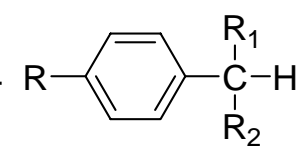

101

$16 \%$

$28 \%$

$18 \%$

$67 \%$ 


\section{Conclusions}

This review describes a number of methods to perform reductive decyanation. A large variety of procedures are available and much of them proceeds with good yields and stereoselectivities allowing their exploitation in organic synthesis. The most popular one is probably the reductive decyanation using metal dissolving conditions. This methodology was first restricted to tertiary nitriles, poor yields were obtained with primary and secondary nitriles. Improvements using HMPA with a protic cosolvent or the $\mathrm{K} /$ dicyclohexano-18-crown-6/toluene system allow decyanation of all classes of nitriles with good yields. The hydride reduction of $\alpha$-aminonitriles is also a well-explored reaction. The success of the decyanation process depends on the substitution pattern of the $\alpha$-aminonitrile, the stereoelectronic effects and the strain of the molecule. Factors promoting the formation of the iminium ion also favored the decyanation over the reduction to diamine. Acid or basic promoted decyanation usually requires harsh conditions, nevertheless, several applications are now described. The reduction under radical conditions was first restricted to geminal dinitriles. Extension to $\alpha$-cyanoesters using $\mathrm{SmI}_{2}$ could open new perspectives.

Different mechanisms were proposed depending on the reducing agent used : electron transfer (alkali metals), radical chain $\left(\mathrm{Bu}_{3} \mathrm{SnH}\right)$ reaction or $\mathrm{S}_{\mathrm{N}} 1$ reaction (metal hydrides with $\alpha$ aminonitriles). Sometimes the mechanism involved remains a puzzle. Thus, the mechanism of decyanation of substrates other than $\alpha$-aminonitriles induced by $\mathrm{LiAlH}_{4}$ is not yet totally clarified. $^{94,97}$ Several pathways were proposed with organometallic reagents, a 4-centered transition state, an addition-elimination process or an electron transfer mechanism. Similarly, the decyanation induced in basic medium could proceed through an addition-elimination process or a sequence involving hydrolysis and decarboxylation.

\section{References}

1. Schaefer, F. C. In The Chemistry of the Cyano Group; Rappoport, Z., Ed.; Interscience: London, 1970; pp 239-305.

2. Arseniyadis, S.; Kyler, K. S.; Watt, D. S. Org. React. (N.Y.) 1984, 31, 1.

3. Fatiadi, A. J. In The Chemistry of Functional Groups, Supplement C; Patai, S., Rappoport, Z., Eds.; John Wiley and Sons: New-York, 1983; pp 1057-1303.

4. Collier, S. J.; Langer, P. Science of Synthesis 2004, 19, 403.

5. Murahashi, S.-I. Science of Synthesis 2004, 19, 345.

6. Barrett, A. G. M. In Comprehensive Organic Synthesis; Trost, B. M., Fleming, I., Eds.; Pergamon Press: Oxford, 1991; Vol. 8, pp 251-257.

7. Mattalia, J.-M.; Samat, A.; Chanon, M. J. Chem. Soc., Perkin Trans. 1 1991, 1769.

8. Ahlbrecht, H.; Raab, W.; Vonderheid, C. Synthesis 1979, 127.

9. Parker, K. A.; Kallmerten, J. L. Tetrahedron Lett. 1979, 1197. 
10. Maeda, H.; Nakatsuji, Y.; Okahara, M. Tetrahedron Lett. 1981, 22, 4105.

11. Arapakos, P. G. J. Am. Chem. Soc. 1967, 89, 6794.

12. Arapakos, P. G.; Scott, M. K.; Huber, Jr., F.E. J. Am. Chem. Soc. 1969, 91, 2059.

13. Marshall, J. A.; Bierenbaum, R. J. Org. Chem. 1977, 42, 3309.

14. Buckmelter, A. J.; Kim, A. I.; Rychnovsky, S. D. J. Am. Chem. Soc. 2000, 122, 9386.

15. Ra, C. S.; Kim, Y. S. Bull. Korean Chem. Soc. 1997, 18, 151.

16. Bunnett, J. F.; Gloor, B. F. J. Org. Chem. 1973, 38, 4156.

17. Vilsmaier, E.; Milch, G.; Bergsträßer, U. Tetrahedron 1998, 54, 6403.

18. Vilsmaier, E.; Herweck, T.; Bergsträßer, U. Tetrahedron 1998, 54, 7417.

19. Rychnovsky, S. D.; Griesgraber, G. J. Chem. Soc., Chem. Commun. 1993, 291.

20. Rychnovsky, S. D.; Dahanukar, V. H. Tetrahedron Lett. 1996, 37, 339.

21. Rychnovsky, S. D.; Dahanukar, V. H. J. Org. Chem. 1996, 61, 7648.

22. Franck-Neumann, M.; Miesch, M.; Lacroix, E.; Metz, B.; Kern, J.-M. Tetrahedron 1992, 48, 1911.

23. Dijksman, W. C.; Verboom, W.; Egberink, R. J. M.; Reinhoudt, D. N. J. Org. Chem. 1985, $50,3791$.

24. Kataoka, F.; Nishida, S.; Tsuji, T.; Murakami, M. J. Am. Chem. Soc. 1981, 103, 6878.

25. Trupp, B.; Handreck, D.-R.; Böhm, H. P.; Knothe, L.; Fritz, H.; Prinzbach, H. Chem. Ber. 1991, 124, 1757.

26. Shishido, K.; Shimada, S.; Fukumoto, K.; Kametani, T. Chem. Pharm. Bull. 1984, 32, 922.

27. Kametani, T.; Suzuki, K.; Nemoto, H. J. Org. Chem. 1982, 47, 2331.

28. Rychnovsky, S. D.; Swenson, S. S. J. Org. Chem. 1997, 62, 1333.

29. Rychnovsky, S. D.; Khire, U. R.; Yang, G. J. Am. Chem. Soc. 1997, 119, 2058.

30. Rychnovsky, S. D.; Yang, G.; Hu, Y.; Khire, U. R. J. Org. Chem. 1997, 62, 3022.

31. Richardson, T. I.; Rychnovsky, S. D. Tetrahedron 1999, 55, 8977.

32. Rychnovsky, S. D.; Zeller, S.; Skalitzky, D. J.; Griesgraber, G. J. Org. Chem. 1990, 55, 5550.

33. Rychnovsky, S. D.; Powers, J. P.; LePage, T. J. J. Am. Chem. Soc. 1992, 114, 8375.

34. Mander, L. N.; McLachlan, M. M. J. Am. Chem. Soc. 2003, 125, 2400.

35. Doumaux, A. R. J. Org. Chem. 1972, 38, 508.

36. Larchevêque, M.; Cuvigny, T. Tetrahedron Lett. 1975, 3851.

37. Cuvigny, T.; Larcheveque, M.; Normant, H. Bull. Soc. Chim. Fr. 1973, 1174.

38. McGrane, P. L.; Livinghouse, T. J. Am. Chem. Soc. 1993, 115, 11485.

39. Savoia, D.; Tagliavini, E.; Trombini, C.; Umani-Ronchi, A. J. Org. Chem. 1980, 45, 3227.

40. Ohsawa, T.; Kobayashi, T.; Mizuguchi, Y.; Saitoh, T.; Oishi, T. Tetrahedron Lett. 1985, 26, 6103.

41. Wender, P. A.; deLong, M. A. Tetrahedron Lett. 1990, 31, 5429.

42. Rychnovsky, S. D.; Mickus, D. E. J. Org. Chem. 1992, 57, 2732.

43. Liu, H.-J.; Yip, J. Synlett 2000, 1119.

44. Guijarro, D.; Yus, M. Tetrahedron 1994, 50, 3447. 
45. Guijarro, D.; Yus, M. Recent Res. Devel. in Organic Chem. 1998, $2,713$.

46. Wolckenhauer, S. A.; Rychnovsky, S. D. Tetrahedron 2005, 61, 3371.

47. La Cruz, T. E.; Rychnovsky, S. D. Org. Lett. 2005, 7, 1873.

48. Morin, M. D.; Rychnovsky, S. D. Org. Lett. 2005, 7, 2051.

49. Yamada, S.; Tomioka, K.; Koga, K. Tetrahedron Lett. 1976, 61.

50. Fabre, C.; Hadj Ali Salem, M.; Welvart, Z. Bull. Soc. Chim. Fr. 1975, 178.

51. Fabre, C.; Welvart, Z. Bull. Soc. Chim. Fr. 1965, 2620.

52. Arseniyadis, S.; Huang, P. Q.; Piveteau, D.; Husson, H.-P. Tetrahedron 1988, 44, 2457.

53. Bunnelle, W. H.; Shevlin, C. G. Tetrahedron Lett. 1989, 30, 4203.

54. Zeller, E.; Sajus, H.; Grierson, D. S. Synlett 1991, 44.

55. Zeller, E.; Grierson, D. S. Heterocycles 1988, 27, 1575.

56. Fabre, C.; Welvart, Z. C. R. Acad. Sc. Paris, Ser C 1970, 270, 1887.

57. Bonin, M.; Romero, J. R.; Grierson, D. S.; Husson, H.-P. Tetrahedron Lett. 1982, 23, 3369.

58. Ratovelomanana, V.; Royer, J.; Husson, H.-P. Tetrahedron Lett. 1985, 26, 3803.

59. Takano, S.; Otaki, S.; Ogasawara, K. J. Chem. Soc., Chem. Commun. 1983, 1172.

60. Devijver, C.; Macours, P.; Braekman, J.-C.; Daloze, D.; Pasteels, J. M. Tetrahedron 1995, $51,10913$.

61. Huang, P. Q.; Arseniyadis, S.; Husson, H.-P. Tetrahedron Lett. 1987, 28, 547.

62. Shirai, M.; Nishiwaki, T. J. Chem. Res. Miniprint 1990, 2018.

63. Yue, C.; Gauthier, I.; Royer, J.; Husson, H.-P. J. Org. Chem. 1996, 61, 4949.

64. Yue, C.; Royer, J.; Husson, H.-P. J. Org. Chem. 1990, 55, 1140.

65. Yamada, S.; Akimoto, H. Tetrahedron Lett. 1969, 3105.

66. Santoyo-González, F.; Hernández-Mateo, F.; Vargas-Berenguel, A. Tetrahedron Lett. 1991, 32, 1371.

67. Nagasaka, T.; Hayashi, H.; Hamaguchi, F. Heterocycles 1988, 27, 1685.

68. Takahashi, K.; Kurita, H.; Ogura, K.; Iida, H. J. Org. Chem. 1985, 50, 4368.

69. Takahashi, K.; Aihara, T.; Ogura, K. Chem. Lett. 1987, 2359.

70. Peng, S.; Guo, M.; Winterfeldt, E. Liebigs Ann. Chem. 1993, 137.

71. Compernolle, F.; Saleh, M. A.; Van den Branden, S. V.; Toppet, S.; Hoornaert, G. J. Org. Chem. 1991, 56, 2386.

72. Okamura, K.; Yamada, S. Chem. Pharm. Bull 1978, 26, 2305.

73. Chauvière, G.; Tchoubar, B.; Welvart, Z. Bull. Soc. Chim. Fr. 1963, 1428.

74. Morris, G. F.; Hauser, C. R. J. Org. Chem. 1962, 27, 465.

75. Zhu, J.; Quirion, J.-C.; Husson, H.-P. J. Org. Chem. 1993, 58, 6451.

76. Miyano, S.; Yamashita, O.; Sumoto, K.; Shima, K.; Hayashimatsu, M.; Satoh, F. J. Heterocycl. Chem. 1987, 24, 47.

77. Rajagopalan, P.; Advani, B. G. Tetrahedron Lett. 1965, 2197.

78. Liu, Y. X.; Liang, X. T. Chin. Chem. Lett. 2001, 12, 7.

79. Guerrier, L.; Royer, J.; Grierson, D. S.; Husson, H.-P. J. Am. Chem. Soc. 1983, 105, 7754.

80. Royer, J.; Husson, H.-P. J. Org. Chem. 1985, 50, 670. 
81. Ogura, K.; Shimamura, Y.; Fujita, M. J. Org. Chem. 1991, 56, 2920.

82. Baldwin, J. E.; Spring, D. R.; Whitehead, R. C. Tetrahedron Lett. 1998, 39, 5417.

83. Meyer, N.; Werner, F.; Opatz, T. Synthesis 2005, 945.

84. Sassaman, M. B. Tetrahedron 1996, 52, 10835.

85. Amos, D. T.; Renslo, A. R.; Danheiser, R. L. J. Am. Chem. Soc. 2003, 125, 4970.

86. Stevens, R. V. Acc. Chem. Res. 1984, 17, 289.

87. Lienard, P.; Quirion, J.-C.; Husson, H.-P. Tetrahedron 1993, 49, 3995.

88. Polniaszek, R. P.; Belmont, S. E. J. Org. Chem. 1990, 55, 4688.

89. Polniaszek, R. P.; Belmont, S. E. J. Org. Chem. 1991, 56, 4868.

90. Posson, H.; Hurvois, J.-P.; Moinet, C. Synlett 2000, 209.

91. Bruylants, P. Bull. Soc. Chim. Belg. 1924, 33, 467.

92. Garratt, P. J.; Doecke, C. W.; Weber, J. C.; Paquette, L. A. J. Org. Chem. 1986, 51, 449.

93. Black, D. S. C.; Doyle, J. E. Aust. J. Chem. 1978, 31, 2323.

94. Mattalia, J.-M.; Bodineau, N.; Négrel, J.-C.; Chanon, M. J. Phys. Org. Chem. 2000, 13, 233.

95. March, J. Advanced Organic Chemistry; Fourth ed.; Wiley: New York, 1992.

96. Németh, G.; Poszávácz, L.; Bózsing, D.; Simig, G. J. Fluorine Chem. 1996, 78, 87.

97. Mattalia, J.-M.; Berchadsky, Y.; Péralez, E.; Négrel, J.-C.; Tordo, P.; Chanon, M. Tetrahedron Lett. 1996, 37, 4717. For this paper, we apologize for the misleading last sentence in the abstract, one should read : electrochemical measurements do not fit with a SET from $\mathrm{LiAlH}_{4}$ to the nitrile.

98. Ashby, E. C.; Welder, C. O. J. Org. Chem. 1997, 62, 3542.

99. Klenk, M. M.; Suter, C. M.; Archer, S. J. Am. Chem. Soc. 1948, 70, 3846.

100.Mosby, W. L. J. Am. Chem. Soc. 1953, 75, 3600.

101.Berkoff, C. E.; Rivard, D. E.; Kirkpatrick, D.; Ives, J. L. Synt. Commun. 1980, 10, 939.

102.Bendale, P. M.; Chowdhury, B. R.; Khadilkar, B. M. Indian J. Chem., Sect. B 2001, 40B, 433.

103. Milart, P.; Wilamowski, J.; Sepiol, J. J. Tetrahedron 1998, 54, 15643.

104. Suresh, J. R.; Barun, O.; Ila, H.; Junjappa, H. Tetrahedron 2000, 56, 8153.

105. Sheverdov, V. P.; Ershov, O. V.; Nasakin, O. E.; Tafeenko, V. A. Russ. J. Org. Chem. 2002, 38, 1068.

106. Satoh, T.; Yoshida, M.; Takahashi, Y.; Ota, H. Tetrahedron: Asymmetry 2003, 14, 281.

107.Alexandre, F.-R.; Berecibar, A.; Wrigglesworth, R.; Besson, T. Tetrahedron Lett. 2003, 44, 4455.

108.Curran, D. P.; Seong, C. M. Synlett 1991, 107.

109. Newcomb, M. In Radicals in Organic Synthesis; Renaud, P., Sibi, M. P., Eds.; Wiley-VCH: Weinheim, 2001; Vol. 1, pp 317-336.

110.Gerlach, U. Tetrahedron Lett. 1995, 36, 5159.

111.Hattori, K.; Grossman, R. B. J. Org. Chem. 2003, 68, 1409.

112. Rychnovsky, S. D.; Swenson, S. S. Tetrahedron 1997, 53, 16489.

113.Kang, H.-Y.; Hong, W. S.; Cho, Y. S.; Koh, H. Y. Tetrahedron Lett. 1995, 36, 7661. 
114.Lee, J. C.; Koh, H. Y.; Lee, Y. S.; Kang, H.-Y. Bull. Korean Chem. Soc. 1997, 18, 783.

115.Molander, G. A.; Wolfe, J. P. J. Braz. Chem. Soc. 1996, 7, 335.

116. Kamochi, Y.; Kudo, T. Yakugaku Zasshi 2000, 120, 245.

117. Marr, G.; Ronayne, J. J. Chem. Soc., Chem. Commun. 1970, 350.

118. Schultz, E. M. J. Am. Chem. Soc. 1952, 74, 5793.

119.Blicke, F. F.; Tsao, E.-P. J. Am. Chem. Soc. 1953, 75, 5587.

120.King, J. A.; Meltzer, R. I.; Doczi, J. J. Am. Chem. Soc. 1955, 77, 2217.

121.Kulp, S. S.; Romanelli, A. Org. Prep. Proced. Int. 1992, 24, 7.

122. Gregory, G. B.; Johnson, A. L.; Ripka, W. C. J. Org. Chem. 1990, 55, 1479.

123.Pearson, A. J.; Khetani, V. D. J. Am. Chem. Soc. 1989, 111, 6778.

124. Mincher, D. J.; Shaw, G. J. Chem. Soc., Chem. Commun. 1986, 1488. For an other example of decyanation of an uracil derivative, see : Kumar, S.; Chimni, S. S. J. Chem. Soc., Perkin Trans. 1 1992, 449.

125.Albaneze-Walker, J.; Zhao, M.; Baker, M. D.; Dormer, P. G.; McNamara, J. Tetrahedron Lett. 2002, 43, 6747.

126.François, D.; Poupon, E.; Lallemand, M.-C.; Kunesch, N.; Husson, H.-P. J. Org. Chem. 2000, 65, 3209.

127.François, D.; Poupon, E.; Kunesch, N.; Husson, H.-P. Eur. J. Org. Chem. 2004, 4823.

128. Morales-Ríos, M. S.; Suárez-Castillo, O. R.; García-Martínez, C.; Joseph-Nathan, P. Synthesis 1998, 1755.

129.Arapakos, P. G.; Scott, M. K. Tetrahedron Lett. 1968, 1975.

130.Shono, T.; Terauchi, J.; Kitayama, K.; Takeshima, Y.; Matsumura, Y. Tetrahedron 1992, $48,8253$.

131.Gennaro, A.; Maran, F.; Maye, A.; Vianello, E. J. Electroanal. Chem. 1985, 185, 353.

132.van Tamelen, E. E.; Rudler, H.; Bjorklund, C. J. Am. Chem. Soc. 1971, 93, 7113.

133.Chang, K.-J.; Rayabarapu, D. K.; Cheng, C.-H. J. Org. Chem. 2004, 69, 4781.

134.Clerici, A.; Porta, O. Tetrahedron Lett. 1980, 21, 1675.

135.Tada, M.; Hamazaki, H.; Tsuzuki, K. J. Heterocycl. Chem. 1985, 22, 977.

136.Ono, I.; Fujiki, Y.; Fujinami, N.; Hoshi, T. Chem. Lett. 1989, 371.

137.Beecroft, R. A.; Davidson, R. S.; Goodwin, D.; Pratt, J. E. Tetrahedron 1984, 40, 4487.

138.Freccero, M.; Mella, M.; Albini, A. Tetrahedron 1994, 50, 2115.

139.Homma, K.; Yamada, S. Chem. Pharm. Bull. 1997, 45, 1198. 